This item was submitted to Loughborough's Research Repository by the author.

Items in Figshare are protected by copyright, with all rights reserved, unless otherwise indicated.

\title{
Global model of an atmospheric-pressure capacitive discharge in helium with air impurities from 100 to 10000 ppm
}

PLEASE CITE THE PUBLISHED VERSION

https://doi.org/10.1088/1361-6595/aaf8e1

\section{PUBLISHER}

(C) IOP Publishing

\section{VERSION}

AM (Accepted Manuscript)

\section{PUBLISHER STATEMENT}

This is the Accepted Manuscript version of an article accepted for publication in Plasma Sources Science and Technology. IOP Publishing Ltd is not responsible for any errors or omissions in this version of the manuscript or any version derived from it. The Version of Record is available online at https://doi.org/10.1088/13616595/aaf8e1.

\section{LICENCE}

CC BY-NC-ND 4.0

\section{REPOSITORY RECORD}

Sun, Bowen, Ding-Xin Liu, Felipe Iza, Sui Wang, Aijun Yang, Zhijie Liu, Ming-Zhe Rong, and Xiao-Hua Wang. 2019. "Global Model of an Atmospheric-pressure Capacitive Discharge in Helium with Air Impurities from 100 to $10000 \mathrm{Ppm}$ ". figshare. https://hdl.handle.net/2134/37125. 
ACCEPTED MANUSCRIPT

\section{Global model of an atmospheric-pressure capacitive discharge in helium with air impurities from 100 to 10000 ppm}

To cite this article before publication: Bowen Sun et al 2018 Plasma Sources Sci. Technol. in press https://doi.org/10.1088/1361-6595/aaf8e1

\section{Manuscript version: Accepted Manuscript}

Accepted Manuscript is "the version of the article accepted for publication including all changes made as a result of the peer review process, and which may also include the addition to the article by IOP Publishing of a header, an article ID, a cover sheet and/or an 'Accepted

Manuscript' watermark, but excluding any other editing, typesetting or other changes made by IOP Publishing and/or its licensors"

This Accepted Manuscript is @ 2018 IOP Publishing Ltd.

During the embargo period (the 12 month period from the publication of the Version of Record of this article), the Accepted Manuscript is fully protected by copyright and cannot be reused or reposted elsewhere.

As the Version of Record of this article is going to be / has been published on a subscription basis, this Accepted Manuscript is available for reuse under a CC BY-NC-ND 3.0 licence after the 12 month embargo period.

After the embargo period, everyone is permitted to use copy and redistribute this article for non-commercial purposes only, provided that they adhere to all the terms of the licence https://creativecommons.org/licences/by-nc-nd/3.0

Although reasonable endeavours have been taken to obtain all necessary permissions from third parties to include their copyrighted content within this article, their full citation and copyright line may not be present in this Accepted Manuscript version. Before using any content from this article, please refer to the Version of Record on IOPscience once published for full citation and copyright details, as permissions will likely be required. All third party content is fully copyright protected, unless specifically stated otherwise in the figure caption in the Version of Record.

View the article online for updates and enhancements. 


\title{
Global model of an atmospheric-pressure capacitive discharge in helium with air impurities from 100 to 10000 ppm
}

\author{
Bowen Sun ${ }^{1}$, Dingxin Liu $^{1 *}$, Felipe Iza $^{2}$, Sui Wang ${ }^{1}$, Aijun Yang ${ }^{1}$, Zhijie Liu ${ }^{1}$, Mingzhe Rong ${ }^{1}$ and Xiaohua \\ Wang $^{1 *}$ \\ ${ }^{1}$ State Key Laboratory of Electrical Insulation and Power Equipment, Centre for Plasma Biomedicine, Xi'an Jiaotong University, \\ 710049, P. R. China \\ ${ }^{2}$ School of Mechanical, Electrical and Manufacturing Engineering, Loughborough University, LE11 3TU, UK
}

Email: liudingxin@mail.xjtu.edu.cn and xhw@mail.xjtu.edu.cn

\begin{abstract}
Helium is a common working gas for cold atmospheric plasmas (CAPs) and this is often mixed with other gases, such as oxygen and nitrogen, to increase its reactivity. Air is often found in these plasmas and it can be either introduced deliberately as a precursor or entrapped in systems that operate in open atmosphere. In either case, the presence of small traces of air can cause a profound change on the composition of the plasma and consequently its application efficacy. In this paper, a global model for He+Air CAPs is developed, in which 59 species and 866 volume reactions are incorporated, and a new boundary condition is used for the mass transport at the interface between the plasma and its surrounding air gas. The densities of reactive species and the power dissipation characteristics are obtained as a function of air concentrations spanning from 100 to $10000 \mathrm{ppm}$. As the air concentration increases, the dominant cation changes from $\mathrm{O}_{2}^{+}$to $\mathrm{NO}^{+}$and then to $\mathrm{NO}_{2}^{+}$, the dominant anion changes from $\mathrm{O}_{2}{ }^{-}$to $\mathrm{NO}_{2}{ }^{-}$and then to $\mathrm{NO}_{3}{ }^{-}$, the dominant ground state reactive oxygen species changes from $\mathrm{O}$ to $\mathrm{O}_{3}$, and the dominant ground state reactive nitrogen species changes from $\mathrm{NO}$ to $\mathrm{HNO}_{2} \cdot \mathrm{O}_{2}$ (a) is the most abundant metastable species and its density is orders of magnitude larger than other metastable species for all air concentrations considered in the study. Ion Joule heating is found important due to the electronegative nature of the plasma, which leads to the fast decrease of electron density when the air concentration is larger than $1000 \mathrm{ppm}$. The generation and loss pathways of important biologically relevant reactive species such as $\mathrm{O}_{2} \mathrm{O}_{2}^{-}, \mathrm{O}_{3}, \mathrm{OH}, \mathrm{H}_{2} \mathrm{O}_{2}, \mathrm{NO}$, $\mathrm{HNO}_{2}, \mathrm{HNO}_{3}$ are discussed and differences with the pathways observed in $\mathrm{He}+\mathrm{O}_{2}, \mathrm{He}+\mathrm{H}_{2} \mathrm{O}, \mathrm{Ar}+\mathrm{Air}$ and pure air plasmas are highlighted. Based on the simulation results, a simplified chemistry set with 47 species and 109 volume reactions is proposed. This simplified model greatly reduces the computational load while maintaining the accuracy of the simulation results within a factor of 2 . The simplified chemistry model is computationally much less intensive, facilitating its integration into multidimensional fluid models for the study of the spatio-temporal evolution of He+Air CAPs.
\end{abstract}




\section{Introduction}

Cold atmospheric plasmas (CAPs) have found use in a wide range of applications such as environmental protection $^{[1]}$, surface modification ${ }^{[2]}$ and biomedicine ${ }^{[3-5]}$. Helium is a commonly used as working gas for CAPs due to its good thermal conductivity and discharge stability. However, industrial helium normally has a purity level lower than $99.99 \%$ and as a result, traces of additional gases such as $\mathrm{N}_{2}$ and $\mathrm{O}_{2}$ are typically present in concentrations larger than 100 parts per million (ppm). Moreover, in many atmospheric-pressure applications helium plasmas are operated in open air and therefore air inevitably mixes into the helium working gas ${ }^{[6,7]}$. Given the large energy of helium and helium dimer metastables, Penning ionization is an important process in these discharges and even traces of gases in the ppm range can have a significant effect on the discharge properties and composition ${ }^{[8]}$.

On one hand, the presence of air in helium plasmas is critical for the production of reactive oxygen species (ROS) and reactive nitrogen species (RNS), which are useful for various applications but on the other hand, the presence of air traces can compromise the plasma stability. Some recent reports have witnessed that gas impurities in the ppm range could dramatically change the plasma characteristics ${ }^{[9-12]}$, maximize the production efficiency of ROS and/or RNS ${ }^{[13]}$ when the concentration of traces are increased to several thousand ppm and cause instabilities of CAPs at higher concentration $^{[14,15]}$. Therefore, helium CAPs are normally operated with admixtures of gases (typically air) in a concentration range of 100 to $10000 \mathrm{ppm}$, a regime where the plasma characteristics as well as the production of reactive species are significantly influenced by the actual background gas composition.

Quantifying the impact of the presence of air in the helium CAPs is of importance, both at a fundamental level, where the production mechanisms of ROS and RNS are not yet fully understood, and technologically, as the production efficiency of ROS and RNS needs to be optimized for different applications.

The chemistry in air-containing CAPs is so complex that quantitative studies have proved to be very challenging. At least dozens of species and hundreds of reactions need to be considered in these plasmas but only a few of the species can be measured with current diagnostic techniques ${ }^{[16]}$. Complimenting experiments, plasma modeling can provide insights into the chemistry of CAPs, Previous studies have used computational fluid models with simplified chemistry sets ${ }^{[17,18]}$ without a rigorous approach for the simplification of the chemistry set or analysis of its accuracy. Global models have been widely used to study the chemistry of CAPs, as they provide a computationally effective way of study of complex plasma chemistry sets as those generated in air containing CAPs. Global models have already been successfully used to study CAPs with complex chemistry such as Ar+humid air ${ }^{[19}, \quad \mathrm{He}+\mathrm{O}_{2}$ with humid air impurities ${ }^{[20]}, \mathrm{Ar}+\mathrm{H}_{2} \mathrm{O}^{[21]}$ and $\mathrm{He}+\mathrm{O}_{2}+\mathrm{H}_{2} \mathrm{O}^{[22]}$. For $\mathrm{He}+$ Air plasmas, global model can provide insights into the different power dissipation channels, species densities, key species and chemical pathways. It is noted that the key species and reactions extracted from global models can then be used in fluid models for the study of plasma space variations $^{[23,24]}$, from which additional insights can be obtained.

In this paper, a global model is developed to study He+Air CAPs with air concentrations spanning from 100 to $10000 \mathrm{ppm}$. Following a comprehensive literature review, 59 chemical species and 866 volume reactions are incorporated in the model. The density of reactive species and the power dissipation of various physiochemical processes are discussed in detail as a function of the air concentration in the background gas. Due to their application relevance, special attention is paid on the chemical pathways of ROS and RNS. Careful analysis of the simulation results, allow us to identify the main species and reactions to create a simplified chemistry model. This model incorporates 47 species and 109 volume reactions, $\sim 12 \%$ of the chemical reactions in the original model. The accuracy of the simplified model is assessed by comparing selected reactive species simulation results of the simplified model against those of the original model. Our goal is to explain the plasma chemistry of He+Air CAPs and develop a simplified chemistry set for incorporation in more elaborate fluid models in future study.

The paper is structured as follows. The description of the global model is given in section 2. Simulation results of the full global model are presented in section 3, where the densities of reactive species and power dissipations are discussed as a function of the air concentration in the feed gas. In section 4 , simulation results of the simplified model are presented, where the accuracy and robustness are discussed, and the main pathways for the generation/loss of selected reactive species are illustrated. Finally, concluding remarks are given in section 5 .

\section{Global model}

The global model used in this work is similar to that recently reported and used for the study of $\mathrm{Ar}+\mathrm{H}_{2} \mathrm{O}$ plasmas [25]. Therefore, only the main differences between the two models are described here. Emphasis is made on the new species and chemical reactions, which are significantly different to those in $\mathrm{Ar}+\mathrm{H}_{2} \mathrm{O}$ plasmas, as well as the improved modeling of the radial loss of neutral species.

Figure 1 shows a schematic diagram of the He+Air plasma system considered in this study. It consists of two parallel circular plates with radius $\mathrm{R}=1 \mathrm{~cm}$, with a gap between the two of $\mathrm{g}=2 \mathrm{~mm}$. The plasma is excited with an average power density of $10 \mathrm{~W} / \mathrm{cm}^{3}$, the neutral gas temperature is set to remain at room temperature $(300 \mathrm{~K})$, and the gas flow rate is set to be 100 standard cubic centimeter per minute $(\mathrm{sccm})$. The air concentration in the 
$\mathrm{He}+$ Air feedstock gas is varied from $100 \mathrm{ppm}$ to $10000 \mathrm{ppm}$, and the air is assumed to have a composition of $79 \% \mathrm{~N}_{2}, 20 \%$ $\mathrm{O}_{2}$ and $1 \% \mathrm{H}_{2} \mathrm{O}\left(1 \% \mathrm{H}_{2} \mathrm{O}\right.$ corresponds to a relative humidity of approximately $30 \%$ at $300 \mathrm{~K}$ and 1 atmosphere, which is a typical inland air humidity) ${ }^{[26,27]}$.

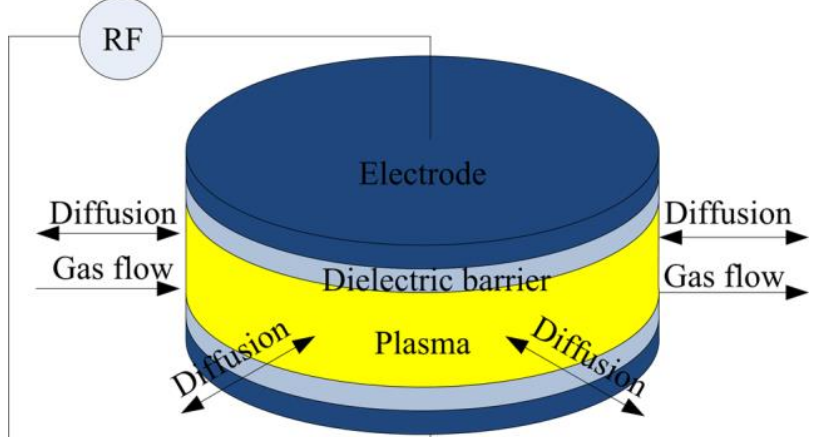

Figure 1. Schematic diagram of the model

The model incorporates 59 species and 866 volume reactions, in which 53 species and 624 reactions are identical to a comprehensive model for air plasmas previously reported by Sakiyama et $a l^{[26]}$. The additional 6 species and 242 volume reactions are all helium-related, which have been identified after an extensive literature review. The incorporated helium species are $\mathrm{He}, \mathrm{He}^{*}, \mathrm{He}_{2}{ }^{*}$, $\mathrm{He}^{+}, \mathrm{He}_{2}{ }^{+}$and $\mathrm{HeH}^{+}$, and the helium-related reactions are listed in the Appendix I. Since we are mainly interested in the biomedical application of these plasmas, the paper focuses on biologically relevant reactive components. Hydrated species often encountered in high humidity plasmas and high order clusters such as $\mathrm{O}_{6}{ }^{+}$are assumed to be negligible for the conditions of this study. The total species, including cations, anions, metastables and ground-state neutrals are listed in table 1. Most rate coefficients are taken from literature and where possible electron collision reaction coefficients are calculated based on cross section data using BOLSIG ${ }^{+[28]}$. When both rate coefficients and cross section data are not available, rates have been estimated according to the recommendations by Kushner and Kossyi et al. [29,53].

Table 1. Species included in this model

\begin{tabular}{|c|c|}
\hline Type & Species \\
\hline $\begin{array}{l}\text { Positive charge } \\
\text { species }\end{array}$ & $\begin{array}{l}\mathrm{He}^{+}, \mathrm{He}_{2}^{+}, \mathrm{HeH}^{+}, \mathrm{N}^{+}, \mathrm{N}_{2}^{+}, \mathrm{N}_{3}^{+}, \mathrm{N}_{4}^{+}, \mathrm{O}^{+}, \mathrm{O}_{2}^{+}, \\
\mathrm{O}_{4}^{+}, \mathrm{NO}^{+}, \mathrm{N}_{2} \mathrm{O}^{+}, \mathrm{NO}_{2}^{+}, \mathrm{H}^{+}, \mathrm{H}_{2}^{+}, \mathrm{H}_{3}^{+}, \mathrm{OH}^{+}, \\
\mathrm{H}_{2} \mathrm{O}^{+}, \mathrm{H}_{3} \mathrm{O}^{+}\end{array}$ \\
\hline $\begin{array}{l}\text { Negative charge } \\
\text { species }\end{array}$ & $\begin{array}{l}\mathrm{e}, \mathrm{O}^{-}, \mathrm{O}_{2}^{-}, \mathrm{O}_{3}^{-}, \mathrm{O}_{4}^{-}, \mathrm{NO}^{-}, \mathrm{N}_{2} \mathrm{O}^{-}, \mathrm{NO}_{2}^{-}, \mathrm{NO}_{3}^{-}, \\
\mathrm{H}, \mathrm{OH}^{-}\end{array}$ \\
\hline Metastables & $\begin{array}{l}\mathrm{He}^{*}, \mathrm{He}_{2}, \mathrm{~N}\left({ }^{2} \mathrm{D}\right), \mathrm{N}_{2}(\mathrm{~A}), \mathrm{N}_{2}(\mathrm{~B}), \mathrm{O}\left({ }^{1} \mathrm{D}\right), \\
\mathrm{O}_{2}(\mathrm{a})\end{array}$ \\
\hline Grounded neu & $\begin{array}{l}\mathrm{He}, \mathrm{H}, \mathrm{N}, \mathrm{O}, \mathrm{O}_{3}, \mathrm{NO}, \mathrm{N}_{2} \mathrm{O}, \mathrm{NO}_{2}, \mathrm{NO}_{3}, \mathrm{~N}_{2} \mathrm{O}_{3}, \\
\mathrm{~N}_{2} \mathrm{O}_{4}, \mathrm{~N}_{2} \mathrm{O}_{5}, \mathrm{H}_{2}, \mathrm{OH}, \mathrm{HO}_{2}, \mathrm{H}_{2} \mathrm{O}_{2}, \mathrm{HNO}, \\
\mathrm{HNO}_{2}, \mathrm{HNO}_{3}, \mathrm{~N}_{2}, \mathrm{O}_{2}, \mathrm{H}_{2} \mathrm{O}\end{array}$ \\
\hline
\end{tabular}

The particle balance equation for each plasma species is given by ${ }^{[10]}$ :

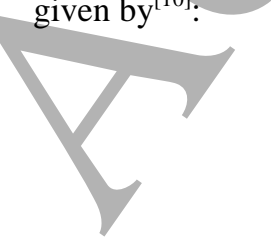

$$
\frac{d n_{k}}{d t}=G_{k}^{V}+\frac{S_{1}}{V}\left(\sum_{i=1, i \neq k}^{N} \alpha_{i, k} \Gamma_{1 i}-\beta_{k} \Gamma_{1 k}\right)-\frac{S_{2}}{V} \Gamma_{2 k}-\frac{F}{V} n_{k}(1)
$$

where $n_{k}$ is the number density of species $k, G_{k}{ }^{V}$ is the net generation/loss rate of species $k$ due to volume reactions in the plasma, $N$ is the total number of species, $S_{1}$ is the total area of the solid plates, $S_{2}$ is the "sidewall" area of the plasma-gas interface, $V$ is the plasma volume, $\Gamma_{1 k}$ is the flux of species $k$ to the solid plates, $\Gamma_{2 k}$ is the flux of species $k$ to the sides out of the plasma, and $F$ is the gas flow rate.

The second term on the right-hand side of equation 1 represents the particle gain/loss due to surface reactions, in which $\beta_{k}$ is the surface reaction probability of species $k$, and $\alpha_{i, k}$ is a parameter between zero and one that relates to the generation probability of species $k$ due to surface reactions of species $i$. All the cations are assumed to be neutralized when reaching the dielectric barriers and therefore $\beta_{k}=1$ for them. Anions are assumed to be confined in the plasma region by the ambipolar field and therefore $\beta_{k} \Gamma_{1 k}=0^{[31,32]}$. Due to the collisionality of the sheaths, the flux of cations is calculated using the following formula ${ }^{[25]}$

$$
\Gamma_{1 k}=\frac{0.6 n_{k} u_{B}}{\sqrt{1+\frac{\pi \lambda_{D s}}{2 \lambda_{\text {ion }}}}}
$$

where $u_{B}$ represents the Bohm velocity, $\lambda_{D s}$ is the Debye length in the plasma sheath, $\lambda_{\text {ion }}$ is the mean free path of positive ions. Finally, the electron flux is set to balance the total flux of cations, maintaining quasi-neutrality in the bulk plasma.

Reactive neutral species are assumed to be absorbed by the dielectric barriers with the value of $\beta_{k}$ varies between zero and one ${ }^{[9]}$. The axial diffusive loss of a reactive species is calculated using the following formula ${ }^{[31]}$

$$
\beta_{k} \Gamma_{1 k}=k_{z}^{2} D_{k} n_{k} g
$$

with

$$
k_{z}^{2}=\left(\frac{g^{2}}{12}+\frac{D_{k} g}{v_{k}} \frac{2-\beta_{k}}{\beta_{k}}\right)^{-1}
$$

where $g$ is the gap length, $D_{k}$ is the diffusion coefficient of species $k$, which is calculated following the approach described in ref. [30]. $v_{k}$ is the thermal mean speed of species $k$. For the derivation of the formulas (2)-(4), please refer to Ref. [25] and [31].

The third term on the right-hand side of equation 1 represents the particle gain/loss due to sidewise diffusion. The sidewise gain and loss are estimated for the neutral species as reported in ref. [31] and [32]. Since only a small proportion of the helium gas is transformed into other species (such as helium metastables), the helium concentration in the feedstock gas is assumed to remain constant in the plasma. However, this is not the case for air species as a large portion of the $\mathrm{N}_{2}, \mathrm{O}_{2}$ and $\mathrm{H}_{2} \mathrm{O}$ molecules are dissociated and/or ionized in the discharge. As a result, the three species $\left(\mathrm{N}_{2}, \mathrm{O}_{2}\right.$ and $\left.\mathrm{H}_{2} \mathrm{O}\right)$ diffuse from the 
surrounding gas into the plasma region, where they are consumed. Following a similar derivation to that in ref. [31], it can be shown that the sidewise flux $\left(\Gamma_{2 k}\right)$ for $\mathrm{N}_{2}, \mathrm{O}_{2}$ and $\mathrm{H}_{2} \mathrm{O}$ at the radial boundary is given by:

$$
\Gamma_{2 k}=\frac{2 D_{k}}{R}\left(1-\frac{n_{k, \text { ext }}^{2}}{n_{k}^{2}}\right) n_{k}
$$

where $k$ represents $\mathrm{N}_{2}, \mathrm{O}_{2}$ and $\mathrm{H}_{2} \mathrm{O}, n_{k, \text { ext }}$ represents the number density of species $k$ in the surrounding (feed) gas, $n_{k}$ the average density of species $k$ in the plasma region, $D_{k}$ is where $n_{k}$ represents the average density of species $k$ across the radial direction, $D_{k}$ represents the diffusion coefficient and $K$ represents the reaction frequency for the destruction (linear approximation) of species k. $v_{t h, k}$ is the mean thermal velocity, $I_{0}$ represents the modified zero-order Bessel function of the first kind. $K$ changes in time as the plasma composition evolves. To account for this time evolution, $K$ is evaluated and updated at each time step in the simulation.

For long-lived species, $K$ is small enough for the loss of species at the boundary to contribute significantly to the loss of particles, and consequently the density at the radial plasma boundary $(n(R))$ is expected to be much lower than the average density in the discharge $\left(n_{\text {ave }}\right)$.

On the other hand, short-lived species are readily lost and therefore the contribution of the radial diffusion out of the plasma region on the lifetime of these species is small. As a result, the radial profile of the density of these species is relatively uniform across the discharge region and the density at the radial boundary of the plasma $(n(R))$ is approximately equal to the average density $\left(n_{\text {ave }}\right)$ in the plasma.

In general, the ratio of the density at the radial boundary to the average density in the discharge $\left(n(R) / n_{a v e}\right)$ is a function of $\mathrm{K}$. As an example, Figure 2 shows this ratio for atomic oxygen as a function of $\mathrm{K}$, when the diffusion coefficient of $\mathrm{O}$ is assumed to be $1 \times 10^{-4} \mathrm{~m}^{2} / \mathrm{s}$. The ratio is calculated using the formula (A11) in Appendix II. The sidewise boundary loss rate $\left(S_{d, i}\right)$ is given by $\Gamma_{2 \mathrm{k}} S_{2} / V$, where $\Gamma_{2 \mathrm{k}}$ is calculated according to equation (6). The loss rate due to chemical reactions is given by $K n_{\text {ave }}$ and $K$ is assumed to varied between $10^{-2}$ to $10^{5}$ for the purposes of Figure 2 .

As the value of $K$ changes due to the time evolution of the plasma composition, the ratio $n(R) / n_{\text {ave }}$ and the radial loss contribution change by orders of magnitude. At low $K$ the diffusion coefficient of species $k$. It is noted that equation (5) given in ref. [31] is just for water, but it should also be applied to $\mathrm{N}_{2}$ and $\mathrm{O}_{2}$ in $\mathrm{He}+$ Air plasmas.

The model also accounts for neutral species were not present in the background gas but are generated in the plasma. These species diffuse outwards and Appendix II details the derivation of an expression for the flux $\Gamma_{2 k}$ of these species at the radial boundary of the discharge region ${ }^{[32]}$. This flux is given by:

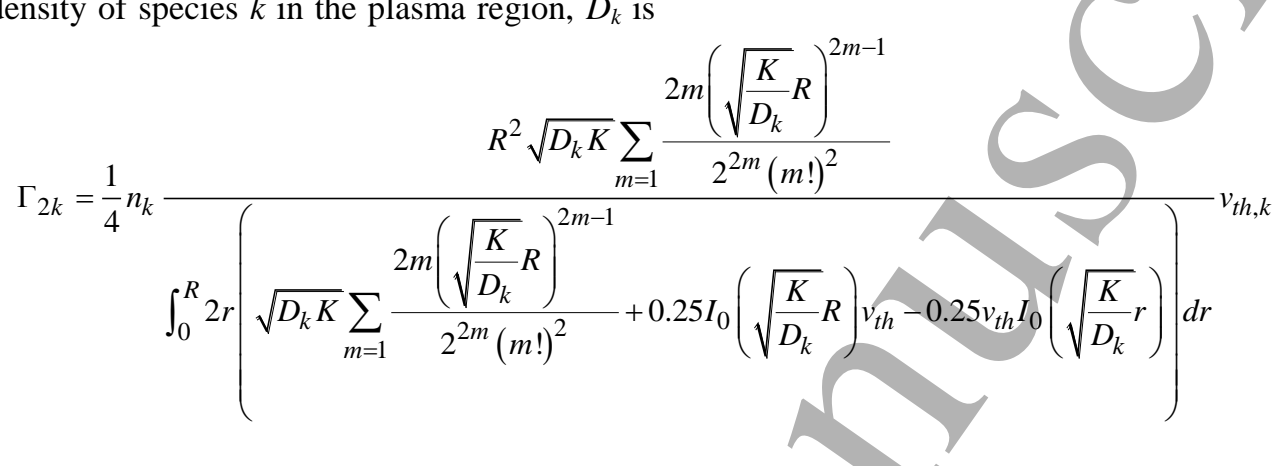

values $\left(K<10 \mathrm{~s}^{-1}\right)$ the ratio $n(R) / n_{\text {ave }}$ is around $2 \times 10^{-4}$ and this increase linearly for $K$ values above $10 \mathrm{~s}^{-1}$. Correspondingly, the sidewise loss contributes nearly $100 \%$ of the loss of atomic oxygen when $K<1 \mathrm{~s}^{-1}$ and this contribution decreases linearly for larger $K$ values, being only $0.6 \%$ when $K=10^{5} \mathrm{~s}^{-1}$. For the steady state conditions encountered in the plasmas investigated in this study, the $K$ value for atomic oxygen is found to be on the order of $10^{3}$ $\mathrm{s}^{-1}$. For very short-lived species such as $\mathrm{O}\left({ }^{1} \mathrm{D}\right), K$ is larger than $10^{6} \mathrm{~s}^{-1}$ and for these species the sidewise loss can be neglected.

Table 2 shows the steady state values of $K$ and the contribution of the sidewise loss to the total loss of the neutral species for the case of an air concentration of 10000 ppm. For short-lived species the sidewise loss accounts for less than $1 \%$ of the total loss and hence the sidewise loss can be neglected for these species without significantly affecting the simulation results. On the other hand, the radial loss can account for more than a quarter of the total losses for long lived species.

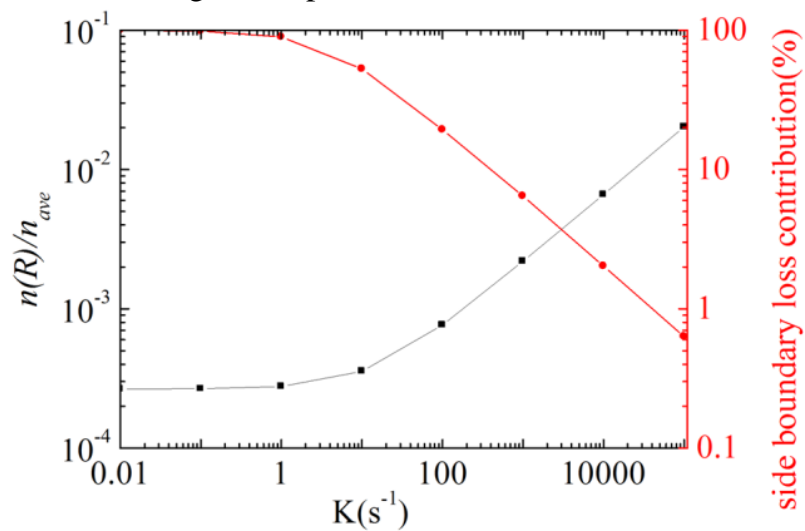

Figure 2. $n(R) / n_{\text {ave }}$ and side boundary loss contribution as a 
function of $\mathrm{K}$ for $\mathrm{O}$ atoms $\left(--n(R) / n_{\text {ave }} ;-\bullet\right.$ : side boundary loss contribution $\left.\left(S_{d, i} /\left(S_{d, i}+K n_{\text {ave }}\right)\right)\right)$

Table 2. Ratio of sidewise loss rate to total loss rate of species for the air impurity of $10000 \mathrm{ppm}$

\begin{tabular}{|c|c|c|c|}
\hline Species & $\bar{K}$ & $\begin{array}{l}\text { Sidewise } \\
\text { contribution }\end{array}$ & loss \\
\hline $\mathrm{N}\left({ }^{2} \mathrm{D}\right)$ & $2.57 \times 10^{5}$ & $0.23 \%$ & \\
\hline $\mathrm{N}_{2}(\mathrm{~A})$ & $1.45 \times 10^{5}$ & $0.36 \%$ & \\
\hline $\mathrm{N}_{2}(\mathrm{~B})$ & $1.98 \times 10^{7}$ & $<0.01 \%$ & \\
\hline $\mathrm{O}\left({ }^{1} \mathrm{D}\right)$ & $9.32 \times 10^{6}$ & $<0.01 \%$ & \\
\hline $\mathrm{H}$ & $1.01 \times 10^{5}$ & $1.00 \%$ & \\
\hline $\mathrm{N}$ & $7.42 \times 10^{3}$ & $2.18 \%$ & \\
\hline $\mathrm{O}$ & $2.61 \times 10^{3}$ & $4.04 \%$ & \\
\hline NO & $2.97 \times 10^{3}$ & $3.03 \%$ & \\
\hline $\mathrm{NO}_{2}$ & $1.18 \times 10^{4}$ & $1.52 \%$ & \\
\hline $\mathrm{NO}_{3}$ & $2.40 \times 10^{4}$ & $0.97 \%$ & \\
\hline $\mathrm{N}_{2} \mathrm{O}_{3}$ & $4.34 \times 10^{5}$ & $0.10 \%$ & \\
\hline $\mathrm{N}_{2} \mathrm{O}_{4}$ & $1.99 \times 10^{5}$ & $0.18 \%$ & \\
\hline $\mathrm{OH}$ & $1.79 \times 10^{4}$ & $1.50 \%$ & \\
\hline $\mathrm{HO}_{2}$ & $1.61 \times 10^{4}$ & $1.35 \%$ & \\
\hline HNO & $5.27 \times 10^{4}$ & $0.74 \%$ & \\
\hline $\mathrm{He}^{*}$ & $4.18 \times 10^{7}$ & $<0.01 \%$ & \\
\hline $\mathrm{He}_{2}{ }^{*}$ & $1.98 \times 10^{7}$ & $<0.01 \%$ & \\
\hline $\mathrm{O}_{3}$ & $8.40 \times 10^{1}$ & $15.88 \%$ & \\
\hline $\mathrm{O}_{2}(\mathrm{a})$ & $5.40 \times 10^{1}$ & $22.10 \%$ & \\
\hline $\mathrm{H}_{2}$ & $1.20 \times 10^{1}$ & $58.32 \%$ & \\
\hline $\mathrm{H}_{2} \mathrm{O}_{2}$ & $1.80 \times 10^{1}$ & $35.80 \%$ & \\
\hline $\mathrm{N}_{2} \mathrm{O}$ & $7.94 \times 10^{2}$ & $5.47 \%$ & \\
\hline $\mathrm{N}_{2} \mathrm{O}_{5}$ & $1.13 \times 10^{2}$ & $10.75 \%$ & \\
\hline $\mathrm{HNO}_{2}$ & $4.50 \times 10^{1}$ & $20.50 \%$ & \\
\hline $\mathrm{HNO}_{3}$ & $5.54 \times 10^{2}$ & $5.88 \%$ & \\
\hline
\end{tabular}

Solution of the balance equation requires knowledge on the electron temperature $\left(\mathrm{T}_{\mathrm{e}}\right)$ and this is calculated by solving the electron energy balance equation: ${ }^{[33]}$

$$
\frac{d}{d t}\left(\frac{3}{2} n_{e} T_{e}\right)=\xi\left(\frac{P_{i n}}{e V}-\frac{S_{1}}{V}\left(\varepsilon_{e} \Gamma_{e}+\sum_{j=1}^{N_{p}} \varepsilon_{p} \Gamma_{1}\right)\right)-\sum_{i=1}^{N_{r}} \varepsilon_{i} R_{i}
$$

where $n_{e}$ represents the electron density, $T_{e}$ the electron temperature, $\xi$ the ratio of power coupled to electrons to the total power (electrons and ions) coupled to the plasma, $e$ the elementary charge, $P_{\text {in }}$ the input power, $N_{r}$ the number of electron impact reactions, $\varepsilon_{i}$ and $R_{i}$ the electron energy loss due to the $i$ th electron impact reaction (including electron-neutral momentum transfer collision) and the corresponding reaction rate, $\varepsilon_{e}$ and $\varepsilon_{p}$ the energy lost per electron and ion escaping the plasma across the sheaths.

Equation (1) and (7) are integrated using COMSOL chemical engineering module to solve for the time evolution of the electron temperature and densities of species.

\section{Simulation results of the full model}

In order to investigate the plasma chemistry of He+Air CAPs, the following cases of air admixture were considered in the study: 100, 200, 500, 1000, 2000, 5000 and 10000 $\mathrm{ppm}$. This range accounts for the typical air concentrations encountered in most applications. The simulation results are discussed below.

A. Densities of reactive species as a function of air concentration

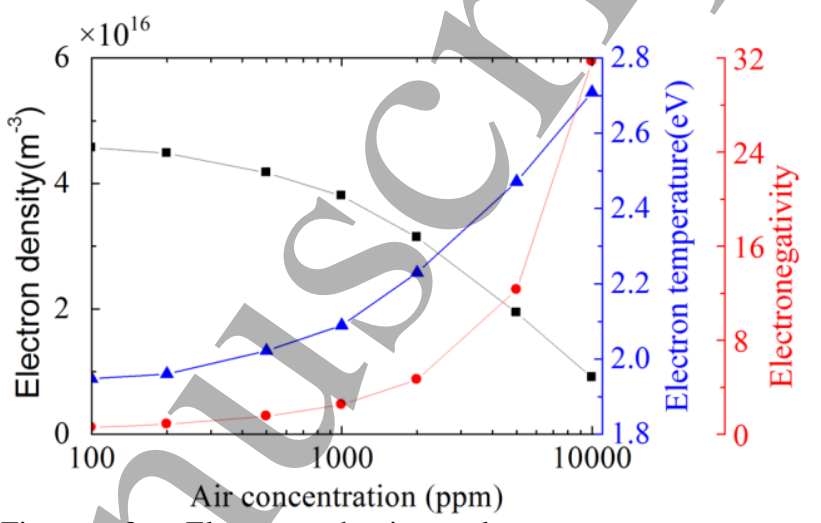

Figure 3. Electron density, electron temperature and electronegativity as a function of air concentration in the feed gas ( - : Electron density; - : Electron temperature; $-\bullet$ : Electronegativity)

The dependence of the electron density, electron temperature and electronegativity on the air concentration is shown in Figure 3. As the air concentration increases from $100 \mathrm{ppm}$ to $10000 \mathrm{ppm}$, the electron density decreases from $4.6 \times 10^{16}$ to $9.1 \times 10^{15} \mathrm{~m}^{-3}$, while the electron temperature increases from $1.95 \mathrm{eV}$ to $2.71 \mathrm{eV}$. It is noted that the electron temperature here is similar with that in previous reports of $\mathrm{He}+\mathrm{H}_{2} \quad(\sim 2.5 \mathrm{eV}), \quad \mathrm{He}+\mathrm{O}_{2} \quad(\sim 2.4 \quad \mathrm{eV})$ and $\mathrm{He}+\mathrm{O}_{2}+$ air $(\sim 2.4 \mathrm{eV})$ plasmas ${ }^{[33,10,34]}$.

The densities of cations generated in $\mathrm{He}+\mathrm{Air}$ CAPs are shown in Figure 4. For clarity, these are presented in two graphs: one showing the density of oxygen-free cations (Figure 4(a)) and another one showing the oxygen-containing cations (Figure 4(b)). In both graphs, the total concentration of cations is illustrated by a dotted line and it can be seen that the cation density rises from $7.2 \times 10^{16}$ to $3.0 \times 10^{17} \mathrm{~m}^{-3}$ when the air concentration in the admixture increases from 100 to $10000 \mathrm{ppm}$. For oxygen-containing cations, the densities of $\mathrm{O}_{4}{ }^{+}, \mathrm{H}_{3} \mathrm{O}^{+}, \mathrm{NO}^{+}$and $\mathrm{NO}_{2}{ }^{+}$increase with the air concentration, whereas the density of other species decreases. For oxygen-free cations, the density as a function of the air concentration in the admixture shows monotonous decrease trend except for $\mathrm{He}^{+}$, which increases obviously as the air concentration increases. This trend is mainly driven by the increasing electron-impact ionization of $\mathrm{He}$ with the increasing electron temperature (Figure 3). At low air concentration ([air] $<150 \mathrm{ppm}$ ), $\mathrm{O}_{2}{ }^{+}$is the most abundant cation. As the air content increases, $\mathrm{NO}^{+}$becomes dominant and at high air concentration ([air]>2000 ppm) $\mathrm{NO}_{2}{ }^{+}$becomes the dominant ion. $\mathrm{O}_{4}{ }^{+}$is not the most abundant cation, but it has a relative large density for all air 
concentrations considered in the study. In $\mathrm{He}+\mathrm{O}_{2}$ plasmas with humid air impurity, $\mathrm{O}_{4}{ }^{+}$was reported to be the most abundant cation ${ }^{[34]}$.

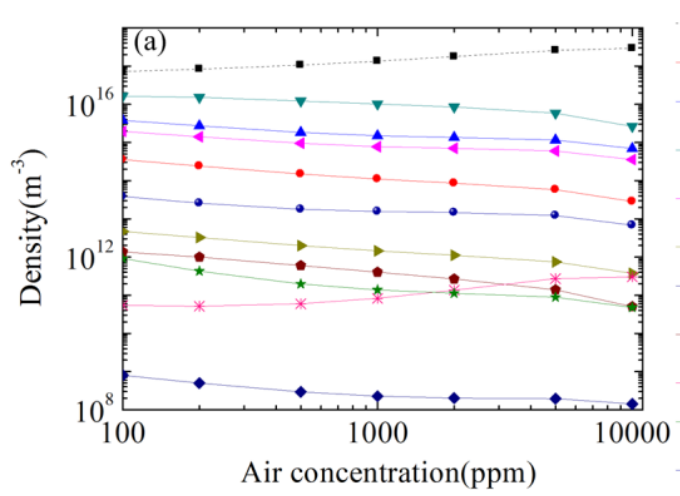

\section{- Total}

- $\mathrm{N}^{+}$

$-\mathrm{N}_{2}^{+}$

$\checkmark \mathrm{N}_{3}^{+}$

$\rightarrow \mathrm{H}^{+}$

- $\mathrm{H}_{2}^{+}$

- $\mathrm{H}_{3}^{+}$

* $\mathrm{He}^{+}$

- $\mathrm{HeH}^{+}$

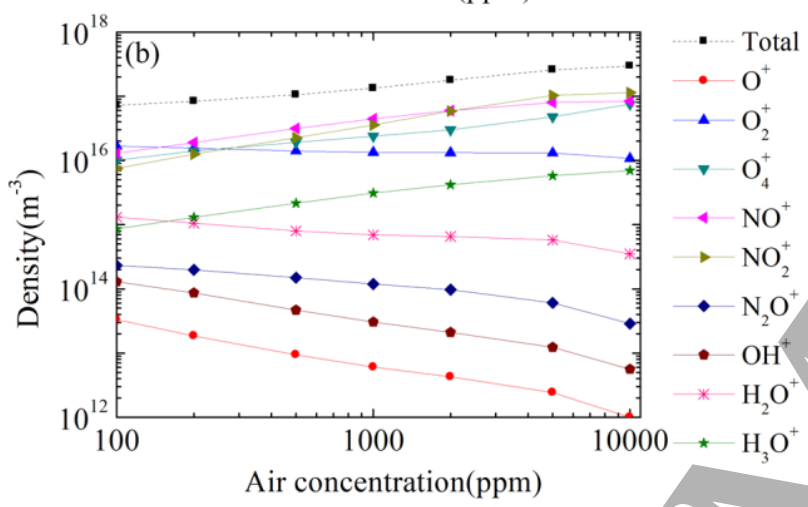

Figure 4. Densities of cations as a function of air concentration: (a) oxygen-free cations; (b) oxygen-containing cations

Similarly to the case of cations, the total anion density increases from $2.7 \times 10^{16}$ to $2.9 \times 10^{17} \mathrm{~m}^{-3}$ when the air concentration rises from 100 to $10000 \mathrm{ppm}$ (Figure 5). It is noted that the electronegativity i.e. the ratio of anion density to electron density, increases with the concentration of air in the feed gas, and the plasma becomes electronegative for air concentrations above $1000 \mathrm{ppm}$ (Figure 3).

The concentration of some anions, such as $\mathrm{NO}_{3}{ }^{-}, \mathrm{NO}_{2}{ }^{-}$, $\mathrm{O}_{4}^{-}, \mathrm{H}^{-}$and $\mathrm{O}_{3}{ }^{-}$, increase with the air concentration, whereas the density of $\mathrm{NO}^{-}$first increases then decreases at high air concentration. Significantly, biologically relevant species such as $\mathrm{O}_{2}^{-}$are found to be produced in relatively large quantities. The density of $\mathrm{O}_{2}^{-}$decreases slightly as air content increases and it is the most abundant anion at low air concentrations $(<300 \mathrm{ppm})$. As the air concentration increases above $300 \mathrm{ppm}, \mathrm{NO}_{2}^{-}$and $\mathrm{NO}_{3}^{-}$become the dominant species. It is noted that the density of $\mathrm{NO}_{3}{ }^{-}$has a significant increase of about three orders of magnitude as the air content increases from 100 to $10000 \mathrm{ppm}$. As a result, $\mathrm{NO}_{3}{ }^{-}$becomes the most abundant anion for [air] $>2000 \mathrm{ppm}$. This is due to the large electron affinity $(3.9 \mathrm{eV})$ of $\mathrm{NO}_{3}{ }^{-[65]}$, and the increasing density of $\mathrm{NO}_{2}^{-}$for charge transfer reactions to form $\mathrm{NO}_{3}{ }^{-}$.

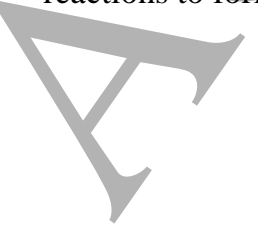

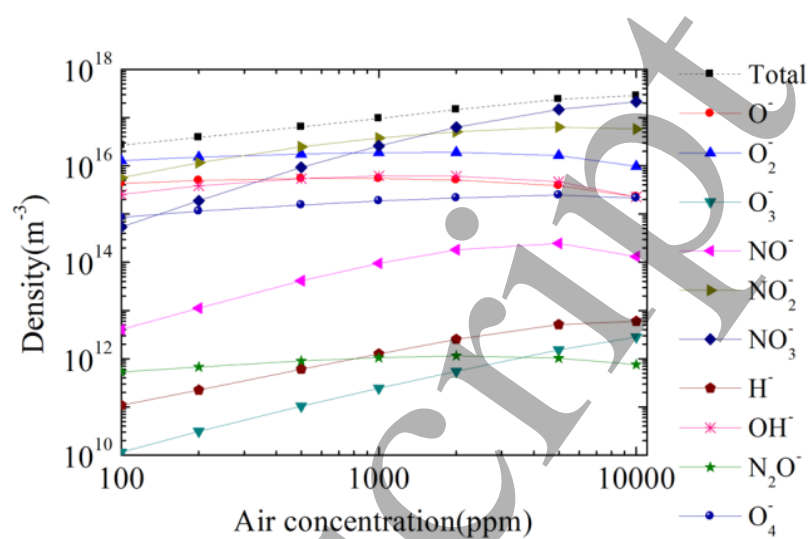

Figure 5. Densities of anions as a function of the air concentration in the feed gas

Figure 6 shows the densities of excited neutral species as a function of the air concentration. The dominant excited neutral species is $\mathrm{O}_{2}(\mathrm{a})$, of which the density increases from $9.8 \times 10^{19}$ to $4.7 \times 10^{21} \mathrm{~m}^{-3}$ as the air concentration in the feed gas changes from 100 to $10000 \mathrm{ppm}$. The density of $\mathrm{O}_{2}(\mathrm{a})$ is higher than that of the other excited species by several orders of magnitude, so its density curve nearly overlaps with that of the total excited neutral species (see Figure 6). This is due to the big electron collisional excitation cross section of $\mathrm{O}_{2}$ to form $\mathrm{O}_{2}(\mathrm{a})^{[35]} \cdot \mathrm{O}_{2}(\mathrm{a})$ is an important bio-active species on its own and it is also an important precursor for other bio-active species such as $\mathrm{O}_{3}$. This suggests that $\mathrm{O}_{2}(\mathrm{a})$ is likely to play an important role in the biomedical applications of He+Air CAPs.

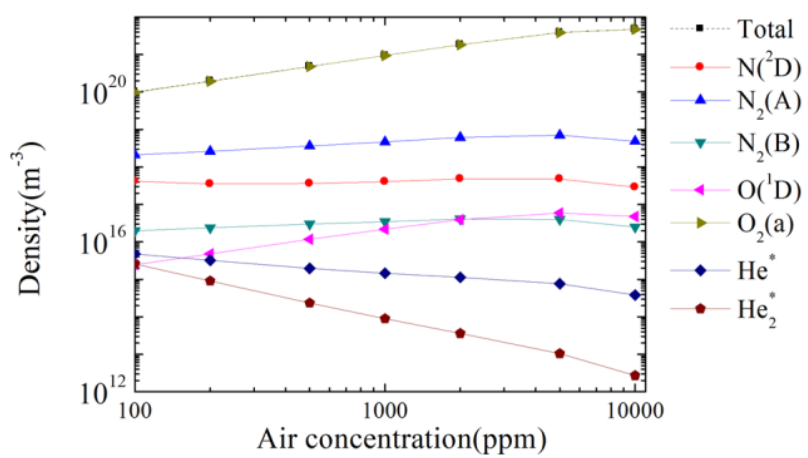

Figure 6. Density of excited neutral species as a function of the air concentration in the feed gas.

Albeit in much lower concentration, $\mathrm{O}\left({ }^{1} \mathrm{D}\right)$ has a very similar density trend to that of $\mathrm{O}_{2}$ (a). This is expected as both species are generated primarily by electron-neutral collisions with $\mathrm{O}_{2}$. Dissociative excitation of $\mathrm{O}_{2}$ to produce $\mathrm{O}\left({ }^{1} \mathrm{D}\right)$ requires $7.1 \mathrm{eV}$ electrons, while only $0.98 \mathrm{eV}$ is required for the excitation of $\mathrm{O}_{2}$ to $\mathrm{O}_{2}$ (a). As a result, the density of $\mathrm{O}\left({ }^{1} \mathrm{D}\right)$ is lower than that of $\mathrm{O}_{2}(\mathrm{a})$ by more than four orders of magnitude.

As shown in Figure 6, $\mathrm{He}^{*}$ and $\mathrm{He}_{2}{ }^{*}$ are present in low concentration but this does not mean that their production rates are small. Helium metastables have high potential energy, $19.8 \mathrm{eV}$ for $\mathrm{He}^{*}$ and $18.4 \mathrm{eV}$ for $\mathrm{He}_{2}{ }^{*}$, and therefore 
they are capable of Penning ionizing air molecules $\left(\mathrm{O}_{2}\right.$ : $\left.12.06 \mathrm{eV} ; \mathrm{N}_{2}: 15.58 \mathrm{eV} ; \mathrm{H}_{2} \mathrm{O}: 12.61 \mathrm{eV}\right)$. These processes have large reaction rates and this is the main reason for the small concentration $\left(<10^{16} \mathrm{~m}^{-3}\right)$ of helium metastables even when the air concentration is just $100 \mathrm{ppm}$. Their densities decrease monotonically with increasing air concentration by one and three orders of magnitude, respectively. Penning ionization has also been identified as an important ionization process in $\mathrm{He}+\mathrm{H}_{2} \mathrm{O}, \mathrm{He}+\mathrm{N}_{2}, \mathrm{He}+\mathrm{O}_{2}$ plasmas $[9,10,36]$.
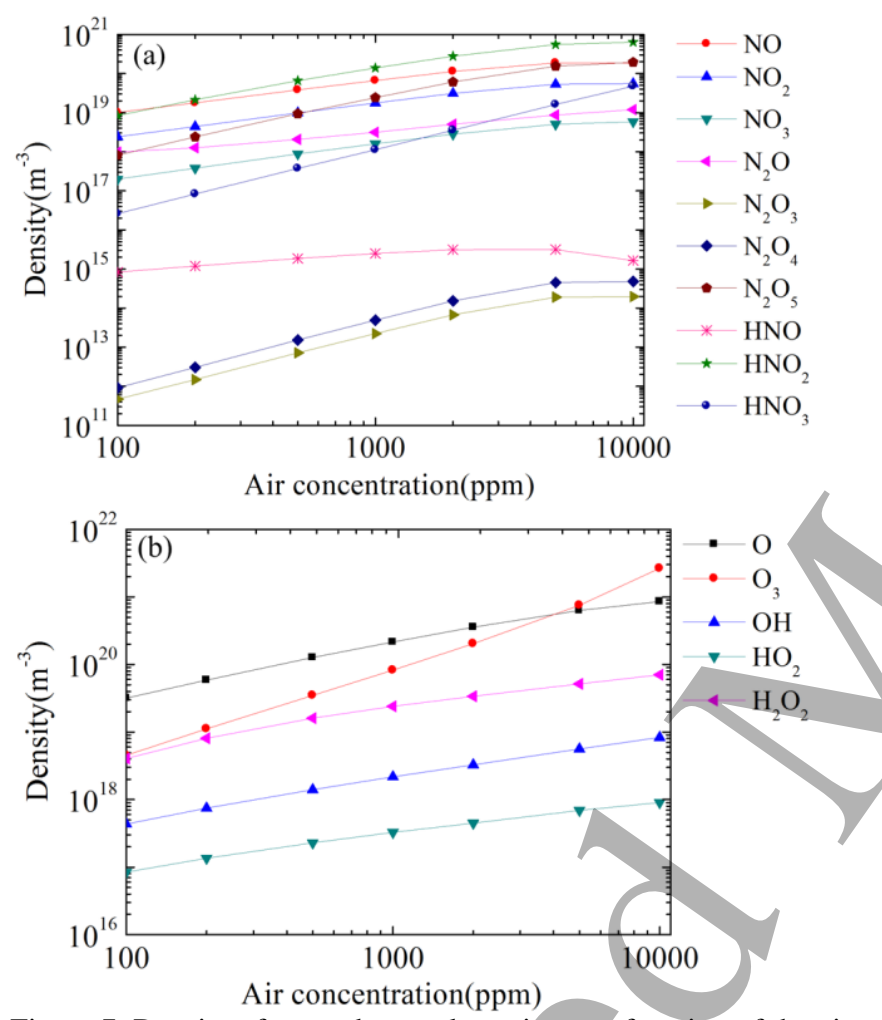

Figure 7. Density of ground neutral species as a function of the air concentration in the feed gas: (a) RNS (b) ROS

The density of ground-state neutral species generated in $\mathrm{He}+\mathrm{Air}$ CAPs as a function of the air/concentration are shown in Figure 7. These are divided into two groups: RNS (Figure 7a) and ROS (Figure 7b). The density of most ROS and RNS increases with the air content in the feedback gas. HNO is the only species that remains approximately constant for the air admixtures considered in this study. The most abundant ground-state species are $\mathrm{O}, \mathrm{O}_{3}, \mathrm{NO}$ and $\mathrm{HNO}_{2}$. The density of $\mathrm{O}$ increases from $3.2 \times 10^{19}$ to $8.5 \times 10^{20} \mathrm{~m}^{-3}$ with the air concentration, and it is the most abundant ground-state ROS when [air] $<5000 \mathrm{ppm}$. O has also been found to be the dominant ROS near the nozzle of argon plasma jets flowing into humid air ${ }^{[37]}$. $\mathrm{O}_{3}$ becomes the dominant ROS when [air] $>5000 \mathrm{ppm}$. For the RNS, NO is the most abundant one at low air concentrations ([air] $<150$ ppm), and then $\mathrm{HNO}_{2}$ becomes the dominant RNS.

In addition, biological reactive species including $\mathrm{OH}$,
$\mathrm{HO}_{2}$ and $\mathrm{H}_{2} \mathrm{O}_{2}$ have similar density trend, and their densities are all above $10^{17} \mathrm{~m}^{-3}$ in the whole air concentration range, indicating that these species would be important in applications of $\mathrm{He}+\mathrm{Air}$ CAPs. The density of $\mathrm{OH}$ is lower than that of $\mathrm{O}$ by two orders of magnitude and this result agrees with observations made in air plasmas ${ }^{[26]}$.

Although the helium concentration is typically at least 99\% of the background gas in He+Air plasmas, helium-containing products (metastables and ions) have very low densities and in generally it can be said that most reactive species originate from air molecules. However, a comparison between an air plasma (ref [26]) and a He+Air plasma (this work) reveal substantial differences. For example, the most abundant ROS in air plasmas is $\mathrm{O}_{3}$, but in $\mathrm{He}+$ Air plasmas $\mathrm{O}_{3}$ only dominates when the air concentration is $>5000 \mathrm{ppm}$. Instead, $\mathrm{O}$ is found to be more abundant than $\mathrm{O}_{3}$ when the air concentration is $<5000 \mathrm{ppm}$. This is primarily due to the lower density of $\mathrm{O}_{2}$ in $\mathrm{He}+\mathrm{Air}$ plasmas and since the main mechanism for ozone formation is the reaction of $\mathrm{O}$ with a reaction $\mathrm{O}_{2}$, a lower molecular oxygen concentration favors the formation of $\mathrm{O}$ in $\mathrm{He}+\mathrm{Air}$ plasmas. The composition of RNS also differs between the $\mathrm{He}+\mathrm{Air}$ and the pure air plasmas. In particular, the densities of $\mathrm{N}_{2} \mathrm{O}_{5}, \mathrm{~N}_{2} \mathrm{O}$ and $\mathrm{HNO}_{3}$ in air plasma are higher by several orders of magnitude than those in He+Air plasmas. Nonetheless, a larger amount of $\mathrm{NO}$ is produced in $\mathrm{He}+\mathrm{Air}$ plasmas ${ }^{[26]}$. These trends observed in He+Air plasmas are similar to those found in $\mathrm{Ar}+\mathrm{Air}$ plasmas ${ }^{[37]}$ as in both cases the concentration of $\mathrm{N}_{2}$ and $\mathrm{O}_{2}$ are diluted by a noble gas. These results indicate that the presence of He can have a dramatic effect on the composition of the cocktail of ROS and RNS produced in air-containing plasmas.

As discussed above, helium ions and metastables have high production rates but their densities are low due to Penning processes and charge transfer reactions ${ }^{[9]}$. This leads to chemical pathways for the generation of reactive species that differ from those encountered in air plasmas. He+Air plasmas are also less electronegative than air discharges and this results in more electrons available for producing reactive species via excitation and dissociation of air molecules.

\section{B. Power dissipation}

Figure 8 shows the main channels in which power is dissipated in He+Air CAPs, as a function of the air concentration. The input power is mainly consumed in elastic collisions (momentum transfer collisions) between electrons and helium molecules. Despite the small energy transfer in each elastic collision, the large collisionality encountered in CAPs results in these collisions dominating the power balance. However, the percentage of energy dissipated via this channel decreases from $95 \%$ to $29 \%$ as the air concentration increases from 100 to $10000 \mathrm{ppm}$, because 1) the number of inelastic collisions increases with 
the introduction of molecular gases $\left(\mathrm{N}_{2}, \mathrm{O}_{2}\right.$ and $\left.\mathrm{H}_{2} \mathrm{O}\right)$, and 2) less power is coupled to electrons as the electronegativity of the plasma increases. The power consumed in electron-impact excitation processes becomes significant as the air content of the feed gas increases above $500 \mathrm{ppm}$ and reaches $15 \%$ at $[$ air $]=10000 \mathrm{ppm}$. The following excitation reactions consume most of the power (the reaction number is from Appendix III):

$$
\begin{gathered}
e+N_{2} \rightarrow N\left({ }^{2} D\right)+N+e \\
e+N_{2} \rightarrow N_{2}(A)+e \\
e+N_{2} \rightarrow N_{2}(B)+e \\
e+O_{2} \rightarrow O\left({ }^{1} D\right)+O+e
\end{gathered}
$$

The increasing power dissipation in electron-impact excitation contributes to the increasing densities of excited neutral species (see Figure 6). In comparison, the power dissipated in other inelastic processes, such as electron-impact ionization, is negligible. Due to the strong electronegative nature of $\mathrm{O}_{2}$, increasing amount of power is coupled to ions as the air concentration in the feed gas increases. About $54 \%$ of the input power is consumed by ion Joule heating when [air] $=10000 \mathrm{ppm}$. Power coupled to the ions has little effect on the plasma chemistry and contributes primarily to gas heating. As the power coupled to the electrons decreases with increasing air concentration, the electron density decreases as shown in Figure 3. These trends of power dissipations in $\mathrm{He}+\mathrm{Air}$ CAPs are similar to those in $\mathrm{He}+\mathrm{O}_{2}$ and $\mathrm{He}+\mathrm{H}_{2}$ plasmas ${ }^{[10,33]}$.

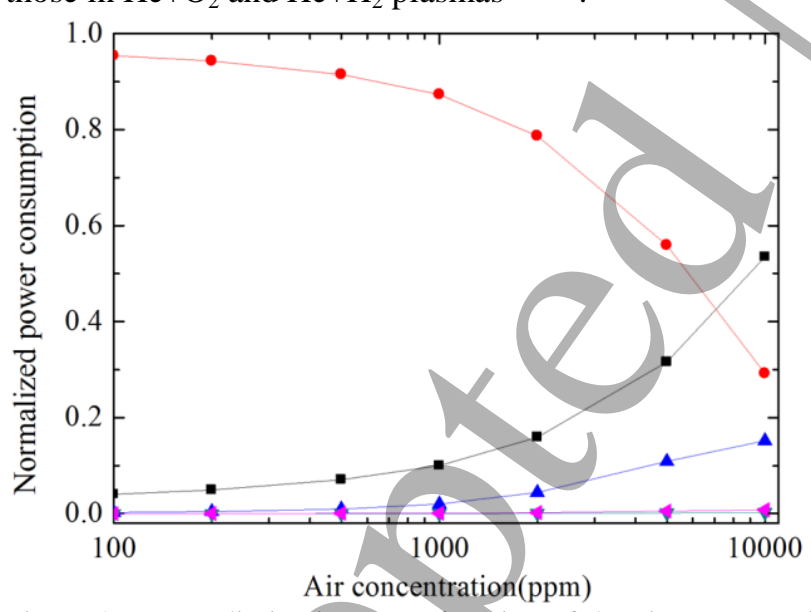

Figure 8. Power dissipations as a function of the air concentration $(-$ : Ion Joule heating $\rightarrow-$ : Elastic collisions $-\bullet$ : Electron excitation $\checkmark$ : Ionization -4 : Other inelastic collisions)

\section{Simulation results of the simplified model}

The model used to obtained the results presented in section 3 incorporates 59 species and 866 reactions. While these can be easily handled by a global model, it is of interest to get a simplified model which can capture the main plasma chemistry but with a reduced set of species and reactions. This simplified chemistry model could then be used in more computationally demanding models to study other spatio-temporal dynamics not accounted for in zero dimensional models.

The criteria for selecting the main species and reactions from the full chemistry model are the same as those used in the study of $\mathrm{He}+\mathrm{H}_{2} \mathrm{O}$ and $\mathrm{He}+\mathrm{O}_{2}$ plasmas ${ }^{[9,10]}$. Briefly, once the simulation has reached steady state, only the species whose densities are larger than a threshold value are deemed important. Here the threshold is set to be the total density of the cations. Besides these main species, some intermediate species whose density doesn't reach the threshold but contribute significantly to the generation/loss of important species are also included in the simplified model.

Once the main species have been selected, the main reactions are chosen next by selecting the reactions whose total contribution to the particle balance of any of the main species exceeds a threshold value of $10 \%$ of the total generation (or loss) for that particular species. After this simplification process, a reduced set of species and chemical reactions consisting of 47 species and 109 volume reactions is obtained. The species in the simplified model are listed in table 3 and the main volume reactions are listed in Appendix III. The number of reactions in the simplified model is $\sim 12 \%$ of those in the full model(original model).

A simplified global model is then developed with the reduced chemistry set and its accuracy and robustness are checked by comparing simulation results against the results obtained with the full global model.

Table 3. Main species

\begin{tabular}{ll}
\hline \multicolumn{1}{c}{ Type } & \multicolumn{1}{c}{ Species } \\
\hline \multirow{2}{*}{ Cations } & $\mathrm{N}^{+}, \mathrm{N}_{2}^{+}, \mathrm{N}_{3}^{+}, \mathrm{N}_{4}{ }^{+}, \mathrm{O}^{+}, \mathrm{O}_{2}{ }^{+}, \mathrm{O}_{4}{ }^{+}, \mathrm{NO}^{+}, \mathrm{NO}_{2}{ }^{+}$, \\
& $\mathrm{OH}^{+}, \mathrm{H}_{2} \mathrm{O}^{+}, \mathrm{H}_{3} \mathrm{O}^{+}$ \\
\hline anions & $\mathrm{e}, \mathrm{O}^{-}, \mathrm{O}_{2}^{-}, \mathrm{O}_{3}^{-}, \mathrm{NO}^{-}, \mathrm{NO}_{2}^{-}, \mathrm{NO}_{3}^{-}, \mathrm{OH}^{-}, \mathrm{H}^{-}$ \\
\hline \multirow{2}{*}{ Metastables } & $\left.\mathrm{He}^{*}, \mathrm{He}_{2}{ }^{*}, \mathrm{~N}^{2} \mathrm{D}\right), \mathrm{N}_{2}(\mathrm{~A}), \mathrm{N}_{2}(\mathrm{~B}), \mathrm{O}\left({ }^{1} \mathrm{D}\right)$, \\
& $\mathrm{O}_{2}(\mathrm{a})$ \\
\hline \multirow{4}{*}{ Grounded neutrals } & $\mathrm{He}, \mathrm{H}, \mathrm{N}, \mathrm{O}, \mathrm{O}_{3}, \mathrm{NO}^{2} \mathrm{~N}_{2} \mathrm{O}, \mathrm{NO}_{2}, \mathrm{NO}_{3}$, \\
& $\mathrm{N}_{2} \mathrm{O}_{5}, \mathrm{H}_{2}, \mathrm{OH}, \mathrm{HO}_{2}, \mathrm{H}_{2} \mathrm{O}_{2}, \mathrm{HNO}_{2}, \mathrm{HNO}_{3}$, \\
& $\mathrm{N}_{2}, \mathrm{O}_{2}, \mathrm{H}_{2} \mathrm{O}$ \\
\hline
\end{tabular}

\section{A. Accuracy and robustness}

The accuracy and robustness of the simplified model can be assessed by comparing the composition of the plasma obtained with the simplified model against the results of the full model (59 species and 866 reactions).

Figure 9 compares the simulation results for the most important ROS and RNS, such as $\mathrm{O}, \mathrm{O}_{3}, \mathrm{H}_{2} \mathrm{O}_{2}, \mathrm{OH}, \mathrm{O}_{2}^{-}, \mathrm{NO}$, $\mathrm{NO}_{3}, \mathrm{HNO}_{2}$ and $\mathrm{HNO}_{3}$ for air concentrations varying from 100 to $10000 \mathrm{ppm}$. It can be seen that the results of the simplified model captures the trends predicted by the full model with a good agreement. 

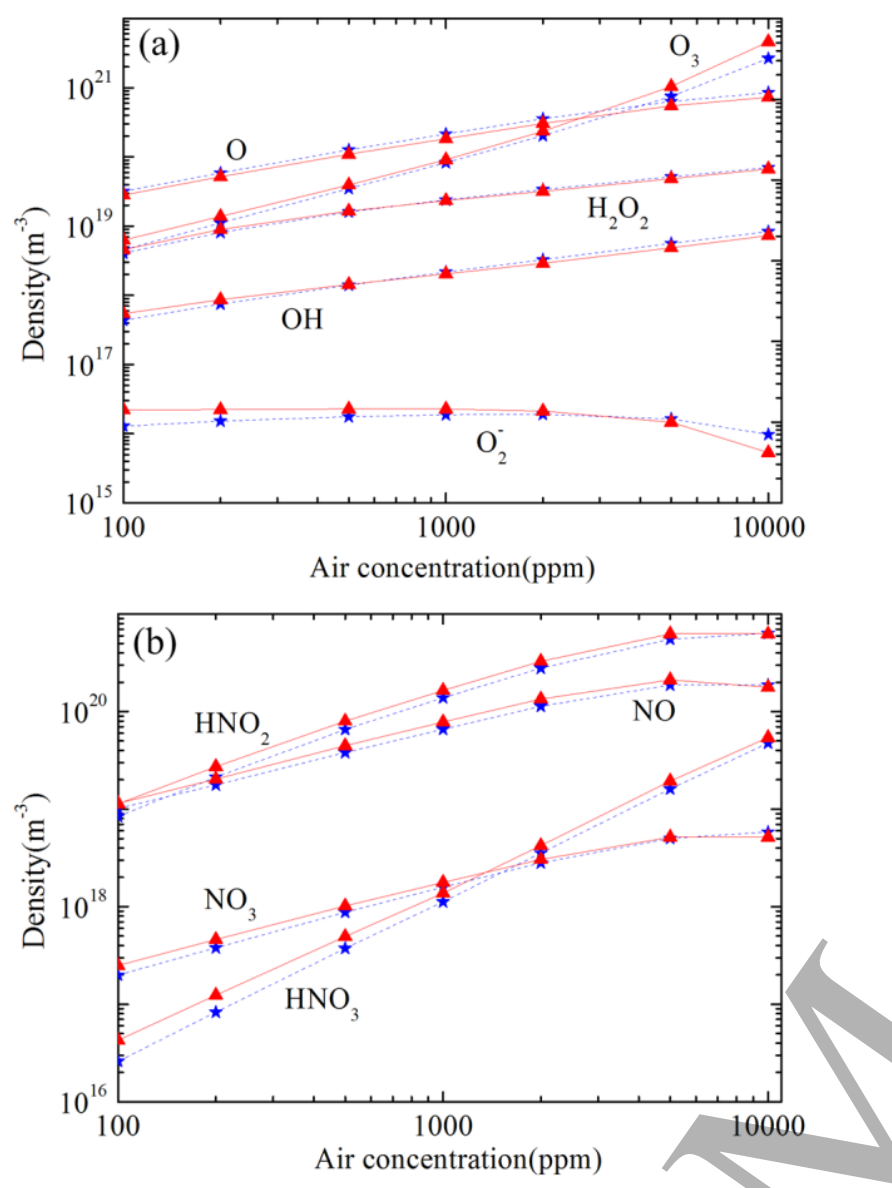

Figure 9. Density of selected (a) ROS and (b) RNS as a function of air concentration: $-\star *$ : full model; $-\mathbf{A}$ : simplified model

The validity and robustness of the simplified model is further investigated by comparing simulation results when the input power and gap distance are doubled. The relative error (RE) of the simplified model is quantified by calculating the root mean squared error for the density of all of the key species in the simplified model:

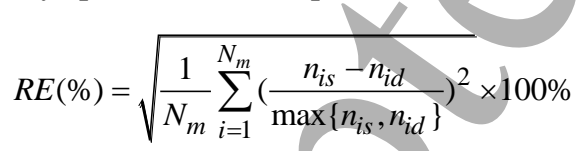

where $N_{m}$ is the total number of species in the simplified model, $n_{i s}$ denotes the density of the $i$ th main species obtained with the simplified model/and $n_{i d}$ is the one obtained with the full model. The relative error incurred by the simplified model under different input power and discharge gap conditions as a function of the air content in the feed gas is shown in Figure 10. For all cases the error is less than $200 \%$ and lower errors $(<60 \%)$ are observed for air concentrations $>1000 \mathrm{ppm}$. These results suggest that the simplified model captures the main chemical pathways despite the changes in applied power and reactor geometry.

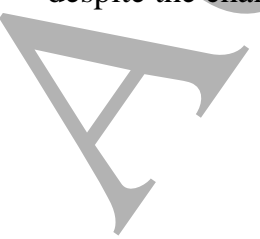

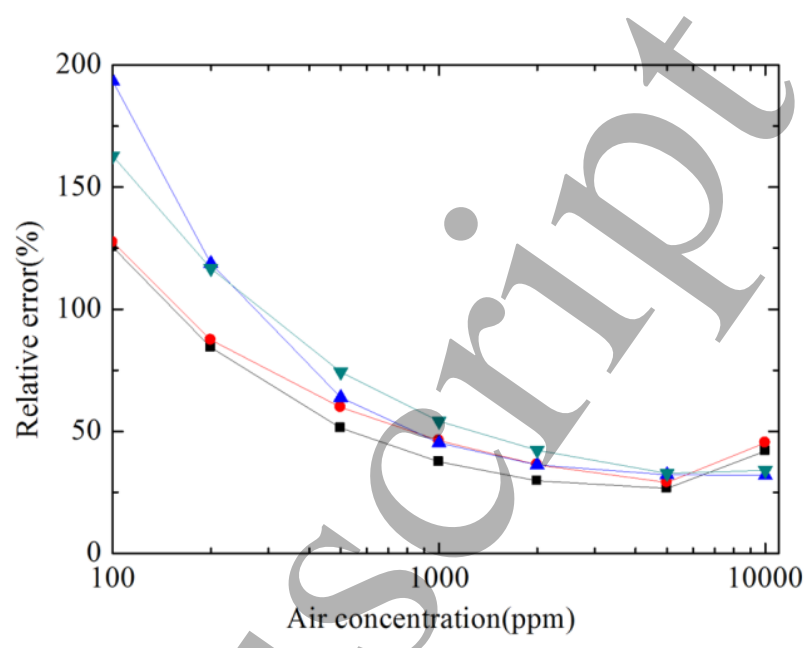

Figure 10. Accuracy of the simplified models with four different discharge conditions. - - $\mathrm{p}=10 \mathrm{~W} / \mathrm{cm}^{3}, \mathrm{~g}=2 \mathrm{~mm} ;-\bullet: \mathrm{p}=10$ $\mathrm{W} / \mathrm{cm}^{3}, \mathrm{~g}=1 \mathrm{~mm} ; \mathrm{p}=20 \mathrm{~W} / \mathrm{cm}^{3}, \mathrm{~g}=2 \mathrm{~mm} ; \boldsymbol{\nabla}: \mathrm{p}=20$ $\mathrm{W} / \mathrm{cm}^{3}, \mathrm{~g}=1 \mathrm{~mm}$

\section{B. Main chemical pathways of selected reactive species}

Figure 11 illustrates the main pathways for the generation and loss of selected biologically relevant species in He+Air CAPs. RNS are shown on the left of the Figure and ROS in the middle and on the right. Simulation results presented in this section are obtained with the simplified model and we focus on the generation and loss of NO, $\mathrm{HNO}_{2}, \mathrm{HNO}_{3}, \mathrm{HO}_{2}, \mathrm{O}, \mathrm{OH}, \mathrm{H}_{2} \mathrm{O}_{2}, \mathrm{O}_{2}^{-}, \mathrm{O}_{3}$ due to the high significance of these ROS and RNS. ${ }^{[5,38]}$ The chemical pathways governing the interaction between these species are discussed next. The reaction numbers used in this section correspond to the reactions listed in Appendix III. It should be noted that in Figure 11 only the chemical pathways relevant to a selection of bio-active species (marked in red) are shown. Chemical pathways for the generation/loss of species not highlighted in red may be missing from Figure 11. For example, reaction R86: $N_{2}(A)+O \rightarrow O\left({ }^{1} D\right)+N_{2}$ is important for the production of $\mathrm{O}\left({ }^{1} \mathrm{D}\right)$ but not shown in Figure 11.

Atomic oxygen $(\mathrm{O})$ is an important ROS which is readily produced in plasmas but is not easily obtained by other means. At low air concentration, $\mathrm{O}$ is primarily produced by collisional relaxation reactions of $\mathrm{O}\left({ }^{1} \mathrm{D}\right)(\mathrm{R} 54)$, followed by dissociation of $\mathrm{O}_{2}$ by excited $\mathrm{N}_{2}$ molecules (R83 and R87) and electron-impact dissociation of molecular oxygen (R8). Although the rate coefficient of R52 is about two orders of magnitude higher than the rate of $\mathrm{R} 54$, the $\mathrm{N}_{2}$ concentration is much lower than the $\mathrm{He}$ concentration when the air concentration is low. As a result, despite its lower reaction rate constant, R54 is the dominant reaction for the production of $\mathrm{O}$. At high air concentration, the dissociation of $\mathrm{O}_{2}$ by excited $\mathrm{N}_{2}$ molecules (R83 and R87) becomes the dominant chemical pathway for the production of $\mathrm{O}$, followed by collisional relaxation reactions 
(R52 and R54) and electron-impact dissociation (R8). This is different from CAPs operated in other gas environment (e.g. $\mathrm{He}+\mathrm{O}_{2}, \mathrm{He}+\mathrm{H}_{2} \mathrm{O}$ ), where electron-impact dissociation of $\mathrm{O}_{2}$ is the dominated mechanism for $\mathrm{O}$ production ${ }^{[10,39]}$.
The present of excited $\mathrm{N}_{2}$ in $\mathrm{He}+\mathrm{Air}$ CAPs enhances the density of $O\left({ }^{1} \mathrm{D}\right)(\mathrm{R} 83)$ and consequently changes the main production pathway of the ground state $\mathrm{O}$.
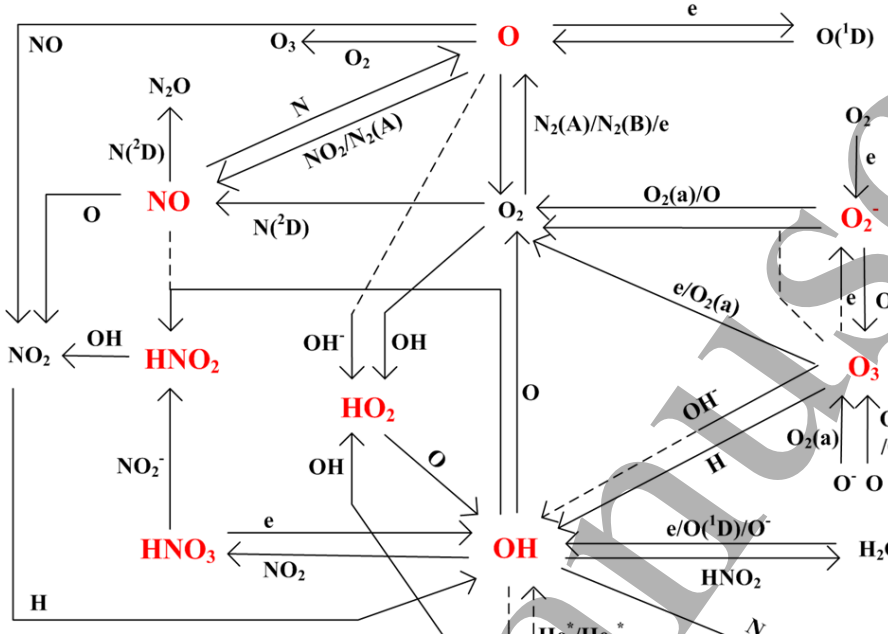

Figure 11. Main chemical pathways for the generation/loss of selected biologically relevant species (highlighted in red) in He+Air CAPs. Dotted lines represent secondary pathways whilst solid lines represent primary pathways. For example, the reaction between $\mathrm{OH}^{-}$and $\mathrm{O}_{3}$ is important pathway for the destruction of $\mathrm{O}_{3}$ but unimportant for the production of $\mathrm{OH}$.

$$
\begin{gathered}
\mathrm{O}+\mathrm{NO}_{2} \rightarrow \mathrm{NO}+\mathrm{O}_{2} \\
\mathrm{He}+2 \mathrm{O} \rightarrow \mathrm{He}+\mathrm{O}_{2} \\
\mathrm{He}+\mathrm{O}_{2}+\mathrm{O} \rightarrow \mathrm{He}+\mathrm{O}_{3} \\
\mathrm{He}+\mathrm{NO}+\mathrm{O} \rightarrow \mathrm{He}+\mathrm{NO}_{2}
\end{gathered}
$$

Superoxide $\left(\mathrm{O}_{2}^{-}\right)$is a well-known oxidizer in biological systems. In $\mathrm{He}+$ Air CAPs, $\mathrm{O}_{2}^{-}$is mainly produced by electron impact attachment (R13) and dissociative attachment (R15). This is different from the main pathway observed in $\mathrm{He}+\mathrm{O}_{2}$ CAPs, in which the reaction $\mathrm{O}+\mathrm{O}_{3}^{-} \rightarrow \mathrm{O}_{2}^{-}+\mathrm{O}_{2}$ is important for the production of $\mathrm{O}_{2}^{-[40]}$. In $\mathrm{He}+$ Air plasmas, however, due to the low density of $\mathrm{O}_{3}{ }^{-}$this mechanism is negligible.

$$
\begin{aligned}
& e+\mathrm{O}_{2} \rightarrow \mathrm{O}_{2}^{-} \\
& e+\mathrm{O}_{3} \rightarrow \mathrm{O}_{2}^{-}+O
\end{aligned}
$$

$\mathrm{O}_{2}^{-}$is mainly destroyed by collisional detachment (R56-R58), followed by charge transfer (R40, R41). R58 is the dominant reaction for the destruction of $\mathrm{O}_{2}{ }^{-}$at low air concentration, but R56 becomes the dominant mechanism at high air concentration as the density of $\mathrm{O}_{3}$ increases rapidly.

$$
\mathrm{O}_{2}^{-}+\mathrm{O}_{3} \rightarrow \mathrm{O}_{3}+\mathrm{O}_{2}+
$$




$$
\begin{aligned}
& \mathrm{O}_{2}{ }^{-}+\mathrm{O} \rightarrow \mathrm{O}_{3}+e \\
& \mathrm{O}_{2}{ }^{-}+\mathrm{O}_{2}(a) \rightarrow 2 \mathrm{O}_{2}+e \\
& \mathrm{O}_{2}{ }^{-}+O \rightarrow O^{-}+\mathrm{O}_{2} \\
& \mathrm{O}_{2}{ }^{-}+\mathrm{O}_{3} \rightarrow \mathrm{O}_{3}{ }^{-}+\mathrm{O}_{2}
\end{aligned}
$$

A number of pathways contribute to the formation of hydroxyl radicals. At low air concentration $\mathrm{OH}$ is mainly produced by electron impact dissociation (R11 and R18), charge transfer (R37), and some reactions between neutral species (R91 and R97). However, when the air concentration is higher than 2000 ppm, R18, R93 and R95 become the dominant pathways for the production of $\mathrm{OH}$ radicals. This is different to $\mathrm{He}+\mathrm{H}_{2} \mathrm{O}$ CAPs, in which electron impact dissociation (R11) is always the most dominant reaction for $\mathrm{OH}$ production ${ }^{[23]}$.

$$
\begin{aligned}
& e+\mathrm{H}_{2} \mathrm{O} \rightarrow \mathrm{OH}+\mathrm{H}+e \\
& e+\mathrm{HNO}_{3} \rightarrow \mathrm{NO}_{2}^{-}+\mathrm{OH} \\
& \mathrm{O}^{-}+\mathrm{H}_{2} \mathrm{O} \rightarrow \mathrm{OH}^{-}+\mathrm{OH} \\
& \mathrm{O}+\mathrm{HO}_{2} \rightarrow \mathrm{OH}+\mathrm{O}_{2} \\
& \mathrm{O}\left({ }^{1} \mathrm{D}\right)+\mathrm{H}_{2} \mathrm{O} \rightarrow 2 \mathrm{OH} \\
& \mathrm{O}_{3}+\mathrm{H} \rightarrow \mathrm{OH}+\mathrm{O}_{2} \\
& \mathrm{NO}_{2}+\mathrm{H} \rightarrow \mathrm{OH}+\mathrm{NO}
\end{aligned}
$$

Regarding the loss of $\mathrm{OH}, \mathrm{R} 76$ is the most responsible at low air concentration, followed by R90, R106 and R108. At high air concentration, R99 becomes important due to the increasing concentration of $\mathrm{HNO}_{2}$, while R76 becomes unimportant because the density of $\mathrm{N}$ decreases with the increasing air concentration.

$$
\begin{aligned}
& \mathrm{N}+\mathrm{OH} \rightarrow \mathrm{H}+\mathrm{NO} \\
& \mathrm{O}+\mathrm{OH} \rightarrow \mathrm{H}+\mathrm{O}_{2} \\
& \mathrm{OH}+\mathrm{HNO}_{2} \rightarrow \mathrm{NO}_{2}+\mathrm{H}_{2} \mathrm{O} \\
& \mathrm{He}+\mathrm{NO}+\mathrm{OH} \rightarrow \mathrm{He}+\mathrm{HNO}_{2} \\
& \mathrm{He}+\mathrm{NO}_{2}+\mathrm{OH} \rightarrow \mathrm{He}+\mathrm{HNO}_{3}
\end{aligned}
$$

At low air concentration, $\mathrm{HO}_{2}$ is mainly produced as a result of electron detachment of $\mathrm{OH}$ upon collision with $\mathrm{O}$ (R59). Other reactions with a significant contribution include R103 and R98. At high air concentration, R103 becomes the dominate process and accounts for $84 \%$ of the total $\mathrm{HO}_{2}$ production, followed by R59 and R98.

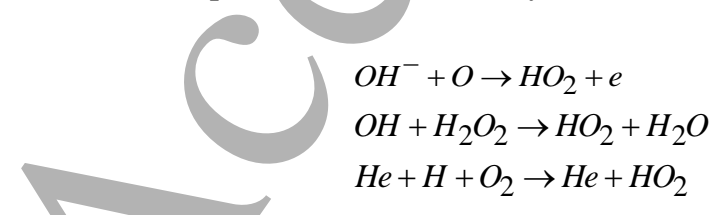

Regarding the loss of $\mathrm{HO}_{2}$, the primary channel is quenching with atomic oxygen (R91), which accounts for more than $90 \%$ of the $\mathrm{HO}_{2}$ destruction for all the air concentrations considered in the study.

$$
\mathrm{O}+\mathrm{HO}_{2} \rightarrow \mathrm{OH}+\mathrm{O}_{2}
$$

$\mathrm{O}_{3}$ is an important ROS produced in many CAPs and typically it is produced by three-body reactions involving $\mathrm{O}$ and $\mathrm{O}_{2}{ }^{[34,40]}$ (R101). In He+Air plasma, however, this reaction is significant for the production of $\mathrm{O}_{3}$ only at high air concentration. At air concentrations below $200 \mathrm{ppm}$, it is found that R55 and R29 account for most of the $\mathrm{O}_{3}$ production. R57 is also significant in the whole range of air concentrations considered in this study.

$$
\begin{aligned}
& \mathrm{O}^{-}+\mathrm{O}_{2}(a) \rightarrow \mathrm{O}_{3}+e \\
& \mathrm{O}_{2}{ }^{+}+\mathrm{O} \rightarrow \mathrm{O}_{3}+e \\
& \mathrm{O}_{4}^{+}+\mathrm{O}^{+} \rightarrow \mathrm{O}_{2}{ }^{+}+\mathrm{O}_{3} \\
& \mathrm{He}+\mathrm{O}_{2}+\mathrm{O} \rightarrow \mathrm{He}+\mathrm{O}_{3}
\end{aligned}
$$

Regarding the loss of ozone, $\mathrm{O}_{3}$ is primarily consumed via electron impact dissociative detachment (R16) at low air concentration. Other contributing reactions are R12 and R46. At high air concentration, the dominant pathways for $\mathrm{O}_{3}$ destruction are R94, R95 and R12.

$$
\begin{aligned}
& e+\mathrm{O}_{3} \rightarrow \mathrm{O}+\mathrm{O}_{2}+e \\
& e+\mathrm{O}_{3} \rightarrow \mathrm{O}^{-}+\mathrm{O}_{2} \\
& \mathrm{OH}^{-}+\mathrm{O}_{3} \rightarrow \mathrm{O}_{3}{ }^{-}+\mathrm{OH} \\
& \mathrm{O}_{2}(\mathrm{a})+\mathrm{O}_{3} \rightarrow \mathrm{O}+2 \mathrm{O}_{2} \\
& \mathrm{O}_{3}+\mathrm{H} \rightarrow \mathrm{OH}+\mathrm{O}_{2}
\end{aligned}
$$

The production of hydrogen peroxide is driven by the three body reaction R104. This is the same mechanism observed in $\mathrm{He}+\mathrm{H}_{2} \mathrm{O}^{[9]}$ and air plasmas ${ }^{[27]}$.

$$
\mathrm{He}+2 \mathrm{OH} \rightarrow \mathrm{He}+\mathrm{H}_{2} \mathrm{O}_{2}
$$

The loss of $\mathrm{H}_{2} \mathrm{O}_{2}$ at low air concentration is primarily driven by Penning ionization reactions (R66 and R71). This contrasts with the dissociative reactions observed in CAPs operated in $\mathrm{Ar}^{[25]}$ and it is the result of the higher energy of helium metastables $\left(\mathrm{He}^{*} 19.8 \mathrm{eV}\right.$ and $\left.\mathrm{He}_{2}{ }^{*} 18.4 \mathrm{eV}\right)$. As the air content in the feed gas is increased, the density of $\mathrm{He}^{*}$ and $\mathrm{He}_{2}{ }^{*}$ decrease (see Figure 6) and at high air content R98 becomes the dominant process.

$$
\begin{aligned}
\mathrm{He}^{*}+\mathrm{H}_{2} \mathrm{O}_{2} & \rightarrow \mathrm{He}+\mathrm{OH}+\mathrm{OH}^{+}+e \\
\mathrm{He}_{2}{ }^{*}+\mathrm{H}_{2} \mathrm{O}_{2} & \rightarrow 2 \mathrm{He}+\mathrm{OH}+\mathrm{OH}^{+}+e \\
\mathrm{H}_{2} \mathrm{O}_{2}+\mathrm{OH} & \rightarrow \mathrm{HO}_{2}+\mathrm{H}_{2} \mathrm{O}
\end{aligned}
$$


Formation of $\mathrm{NO}$ is primarily driven by heavy particle collisions. At low air concentration, the main channel for the production of NO is R88, R79 and R85. As the air content in the feed gas increases, the contribution of R88 becomes the dominant process when [air] $>200 \mathrm{ppm}$. It is noted that R88 is also found important for NO production in $\mathrm{He}+\mathrm{O}_{2}+$ humid air plasmas ${ }^{[34]}$, and $\mathrm{R} 85$ in $\mathrm{Ar}+\mathrm{Air}$ plasmas $^{[37]}$.

$$
\begin{aligned}
& \mathrm{O}_{2}+N\left({ }^{2} D\right) \rightarrow \mathrm{NO}+O\left({ }^{1} D\right) \\
& O+\mathrm{NO}_{2} \rightarrow \mathrm{NO}+\mathrm{O}_{2} \\
& \mathrm{~N}_{2}(A)+O \rightarrow \mathrm{NO}+\mathrm{N}\left({ }^{2} D\right)
\end{aligned}
$$

Regarding the loss of $\mathrm{NO}$, at low air concentration, quenching by atomic nitrogen (R74) is the most important channel. At high air concentration ([air $]>200$ ppm), quenching by atomic oxygen (R102) becomes the dominate pathway. NO destruction by excited nitrogen atoms (R77) has a small but not negligible contribution (1-10\%) for all the air concentrations studied in this work. It is interesting to note that $\mathrm{N}_{2}(\mathrm{D})$ and $\mathrm{O}$ are responsible for the destruction of NO, but on the other hand they are the precursors of NO as discussed above.

$$
\begin{aligned}
& \mathrm{N}+\mathrm{NO} \rightarrow \mathrm{N}_{2}+\mathrm{O} \\
& \mathrm{N}\left({ }^{2} \mathrm{D}\right)+\mathrm{NO} \rightarrow \mathrm{N}_{2} \mathrm{O} \\
& \mathrm{He}+\mathrm{NO}+\mathrm{O} \rightarrow \mathrm{He}+\mathrm{NO}_{2}
\end{aligned}
$$

As for $\mathrm{HNO}_{2}, \mathrm{R} 106$ is the primary pathway for the production of $\mathrm{HNO}_{2}$ and it accounts for over $80 \%$ of the $\mathrm{HNO}_{2}$ production for all the air concentrations considered in the study. $\mathrm{HNO}_{2}$ is primarily quenched by hydroxyl radicals (R99). The dominant pathways for the production and loss of $\mathrm{HNO}_{2}(\mathrm{R} 106$ and R99) are found to be the same as in air plasmas ${ }^{[27]}$ and $\mathrm{Ar}+$ Air plasmas ${ }^{[37]}$. It is interesting to note that $\mathrm{OH}$ plays an crucial role in both the production and destruction of $\mathrm{HNO}_{2}$.

$$
\begin{aligned}
& \mathrm{He}+\mathrm{NO}+\mathrm{OH} \rightarrow \mathrm{He}+\mathrm{HNO}_{2} \\
& \mathrm{HNO}_{2}+\mathrm{OH} \rightarrow \mathrm{NO}_{2}+\mathrm{H}_{2} \mathrm{O}
\end{aligned}
$$

Regarding $\mathrm{HNO}_{3}$, the main chemical pathway for its production is the three body reaction $\mathrm{R} 108$ :

$$
\mathrm{He}+\mathrm{NO}_{2}+\mathrm{OH} \rightarrow \mathrm{He}+\mathrm{HNO}_{3}
$$

Regarding the loss of $\mathrm{HNO}_{3}$, most $\mathrm{HNO}_{3}$ is consumed by electron impact dissociative attachment (R18). This reaction accounts for $95 \%$ of the $\mathrm{HNO}_{3}$ destruction when the air content is $100 \mathrm{ppm}$ and $68 \%$ when the air content is 10000 ppm. Interestingly, the reaction $\mathrm{HNO}_{3}+\mathrm{OH} \rightarrow \mathrm{NO}_{3}$ $+\mathrm{H}_{2} \mathrm{O}$, a key process often believed to dominate the $\mathrm{HNO}_{3}$ destruction $^{[37,27]}$, makes a relatively small contribution $(<1 \%)$

in He+Air CAPs. This is because the rate coefficient of this reaction $\left(1.3 \times 10^{-19} \mathrm{~m}^{3} \mathrm{~s}^{-1}\right)$ is $4-5$ orders of magnitude smaller than that of R18 $\left(5 \times 10^{-14} \mathrm{~m}^{3} \mathrm{~s}^{-1}\right)$. Besides dissociative attachment (R18), R45 also contributes to the destruction of $\mathrm{HNO}_{3}$. This leads to the production of $\mathrm{NO}_{3}^{-}$, which is the dominant anion at high air concentration (see Figure 5).

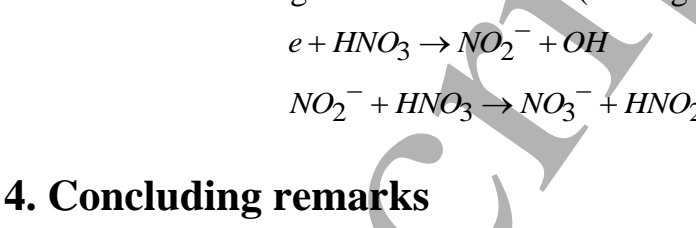

A detailed global model of cold atmospheric-pressure He+Air CAPs that accounts for 59 species and 866 reactions has been developed. The model has been used to identify key species and chemical pathways as the air content in the feed gas varies from 100 to $10000 \mathrm{ppm}$. The model accounts for the radial diffusion in and out of the plasma region, taking into account the lifetime of each species and the different composition of the gas in and out of the plasma.

The density of reactive species and the power dissipation are calculated as a function of air concentration ranging from 100 to $10000 \mathrm{ppm}$. The total density of cations rises from $9.4 \times 10^{16}$ to $3.6 \times 10^{17} \mathrm{~m}^{-3}$ with the increasing air concentration from 100 to $10000 \mathrm{ppm}$, and the dominant cation changes from $\mathrm{O}_{2}{ }^{+}$to $\mathrm{NO}^{+}$and then to $\mathrm{NO}_{2}^{+}$. The total density of anions rises from $2.7 \times 10^{16}$ to $2.9 \times 10^{17} \mathrm{~m}^{-3}$, and the dominant anion changes from $\mathrm{O}_{2}{ }^{-}$to $\mathrm{NO}_{2}{ }^{-}$and then to $\mathrm{NO}_{3}{ }^{-}$. The dominant ground state reactive oxygen species changes from $\mathrm{O}$ to $\mathrm{O}_{3}$, and the dominant ground state reactive nitrogen species changes from $\mathrm{NO}$ to $\mathrm{HNO}_{2}$. $\mathrm{O}_{2}$ (a) is the most abundant metastables, with a density that is several orders of magnitude larger than that of other metastables .

As the air content in the feed gas increases, the discharge becomes increasingly electronegative, and this has a significant effect on the way the power is dissipated in the discharge. At low air concentration, most energy is coupled to the electrons and dissipated primarily via momentum transfer collisions. Inelastic collisions consume an increasing amount of power as air is incorporated in the discharge, which leads to an increasing density of reactive species in the plasma. As the plasma becomes more electronegative, the energy lost via ion Joule heating increases and when the air content in the feed gas is 10000 $\mathrm{ppm}$, it reaches $\sim 54 \%$ of the total energy dissipated in the discharge.

Some significant differences between the plasma chemistry in $\mathrm{He}+\mathrm{Air}$ plasmas and that of previously studied $\mathrm{He}+\mathrm{O}_{2}, \mathrm{He}+\mathrm{H}_{2} \mathrm{O}, \mathrm{Ar}+\mathrm{Air}$ and pure air plasmas have been revealed. Following a careful analysis of the different chemical pathways at play in $\mathrm{He}+$ Air discharges, the main species and reactions have been identified and a simplified discharge model capable of capturing the main physicochemical processes but with only a $\sim 12 \%$ of the 
complexity of the initial model has been created. The validity of the simplified model as the input power and /or the discharge gap size are doubled has also been verified.

From an application point of view, the densities and chemical pathways of biologically relevant species produced in He+Air CAPs provide a new insight into the plasma chemistry of these discharges to guide the operation and optimization of these plasmas in emerging biomedical, agricultural and environmental applications.

\section{Acknowledgement}

This work was supported by the National Science Foundation of China (Grant No. 51722705 and 51521065), and the Fundamental Research Funds for the Central Universities. 


\section{Appendix I: Helium-incorporated reactions in the full model}

\begin{tabular}{|c|c|c|c|}
\hline No. & Reaction & Rate coefficient ${ }^{b}$ & Ref. \\
\hline \multicolumn{4}{|c|}{ Electron impact momentum transfer } \\
\hline 1 & $e+\mathrm{He} \rightarrow e+\mathrm{He}$ & $f\left(T_{e}\right)$ & \\
\hline \multicolumn{4}{|c|}{ Electron impact ionization } \\
\hline 2 & $e+H e \rightarrow 2 e+H e^{+}$ & $f\left(T_{e}\right)$ & \\
\hline 3 & $e+H e^{*} \rightarrow 2 e+H e^{+}$ & $f\left(T_{e}\right)$ & $0^{a^{a}}$ \\
\hline 4 & $e+H e_{2}^{*} \rightarrow H e_{2}^{+}+2 e$ & $9.75 \times 10^{-10}$ & 41 \\
\hline \multicolumn{4}{|c|}{ Electron impact excitation and de-excitation } \\
\hline 5 & $e+H e \rightarrow e+H e^{*}$ & $f\left(T_{e}\right)$ & $9^{\mathrm{a}}$ \\
\hline 6 & $e+H e^{*} \rightarrow \mathrm{He}+e$ & $7 \times 10^{-10}\left(11600 T_{e} / 300\right)^{0.5}$ & 42 \\
\hline 7 & $e+\mathrm{He}_{2}^{*} \rightarrow e+2 \mathrm{He}$ & $4 \times 10^{-9}$ & 43 \\
\hline \multicolumn{4}{|c|}{ Dissociative recombination } \\
\hline 8 & $e+H e^{+} \rightarrow H e$ & $2 \times 10^{-12}$ & 44 \\
\hline 9 & $e+H e^{+} \rightarrow H e^{*}$ & $6.76 \times 10^{-}$ & 45 \\
\hline 10 & $e+\mathrm{He}_{2}{ }^{+} \rightarrow 2 \mathrm{He}$ & $1 \times 10^{-8}$ & 41 \\
\hline 11 & $e+\mathrm{He}_{2}^{+} \rightarrow \mathrm{He}_{2}{ }^{*}$ & 10 & 46 \\
\hline 12 & $e+\mathrm{He}_{2}^{+} \rightarrow \mathrm{He}^{*}+\mathrm{He}$ & $\left.600 T_{e} / T_{g}\right)^{-1.5}$ & 47 \\
\hline 13 & $e+\mathrm{HeH}^{+} \rightarrow \mathrm{H}+\mathrm{He}$ & ר & 48 \\
\hline 14 & $2 e+H e^{+} \rightarrow H e+e$ & $\left.T_{e} / T_{g}\right)^{-4.5}$ & 49 \\
\hline 15 & $2 e+H e^{+} \rightarrow H e^{*}+e$ & $6.0 \times 10^{-20}\left(11600 T_{e} / T_{g}\right)^{-4}$ & 78 \\
\hline 16 & $2 e+\mathrm{He}_{2}^{+} \rightarrow 2 \mathrm{He}+e$ & $7 \times 10^{-20}\left(11600 T_{e} / T_{g}\right)^{-4.5}$ & 49 \\
\hline 17 & $2 e+\mathrm{He}_{2}^{+} \rightarrow \mathrm{He}^{*}+\mathrm{He}+e$ & $2.8 \times 10^{-20}$ & 50 \\
\hline 18 & $2 e+H e_{2}^{+} \rightarrow H$ & $1.2 \times 10^{-21}$ & 50 \\
\hline 19 & $e+H e+H e^{+}$ & $1 \times 10^{-27}$ & 46 \\
\hline 20 & $e+H$ & $2 \times 10^{-27}\left(11600 T_{e} / T_{g}\right)^{-2.5}$ & 49 \\
\hline 21 & $e+\mathrm{He}+\mathrm{He}_{2}^{+} \rightarrow \mathrm{He}^{*}+2 \mathrm{He}$ & $3.5 \times 10^{-27}$ & 50 \\
\hline 22 & $e+\mathrm{He}+\mathrm{He}_{2}^{+} \rightarrow \mathrm{He}_{2}^{*}+\mathrm{He}$ & $1.5 \times 10^{-27}$ & 50 \\
\hline 23 & Te & $6.45 \times 10^{-31}\left(11600 T_{e} / T_{g}\right)^{-2.5}$ & 49 \\
\hline 24 & e & $2 \times 10^{-27}\left(11600 T_{e} / T_{g}\right)^{-2.5}$ & 49 \\
\hline 25 & $e+N_{2}^{+}+\mathrm{He} \rightarrow \mathrm{N}_{2}+\mathrm{He}$ & $3.12 \times 10^{-23} /\left(11600 T_{e}\right)^{1.5}$ & 34 \\
\hline 26 & $e+\mathrm{O}_{2}^{+}+\mathrm{He} \rightarrow \mathrm{O}_{2}+\mathrm{He}$ & $3.12 \times 10^{-23} /\left(11600 T_{e}\right)^{1.5}$ & 34 \\
\hline 27 & $e+\mathrm{NO}^{+}+\mathrm{He} \rightarrow \mathrm{NO}+\mathrm{M}$ & $3.12 \times 10^{-23} /\left(11600 T_{e}\right)^{1.5}$ & 34 \\
\hline \multicolumn{4}{|c|}{ Electron impact attachment } \\
\hline 28 & $e+\mathrm{O}+\mathrm{He} \rightarrow \mathrm{O}^{-}+\mathrm{He}$ & $10^{-31}$ & 10 \\
\hline
\end{tabular}




\begin{tabular}{|c|c|c|c|}
\hline 29 & $e+\mathrm{O}_{2}+\mathrm{He} \rightarrow \mathrm{O}_{2}^{-}+\mathrm{He}$ & $1 \times 10^{-31}$ & 10 \\
\hline 30 & $e+\mathrm{O}_{3}+\mathrm{He} \rightarrow \mathrm{O}_{3}^{-}+\mathrm{He}$ & $1 \times 10^{-31}$ & \\
\hline 31 & $e+\mathrm{OH}+\mathrm{He} \rightarrow \mathrm{OH}^{-}+\mathrm{He}$ & $3 \times 10^{-31}$ & 67 \\
\hline 32 & $e+\mathrm{NO}+\mathrm{He} \rightarrow \mathrm{NO}^{-}+\mathrm{He}$ & $8 \times 10^{-31}$ & \\
\hline 33 & $e+\mathrm{NO}_{2}+\mathrm{He} \rightarrow \mathrm{NO}_{2}^{-}+\mathrm{He}$ & $1.5 \times 10^{-30}$ & 52 \\
\hline 34 & $e+\mathrm{NO}_{3}+\mathrm{He} \rightarrow \mathrm{NO}_{3}^{-}+\mathrm{He}$ & $1 \times 10^{-30}$ & 52 \\
\hline \multicolumn{4}{|c|}{ Ion-ion recombination } \\
\hline 35 & $\mathrm{He}^{+}+\mathrm{O}^{-} \rightarrow \mathrm{O}+\mathrm{He}$ & $2 \times 10^{-7}\left(T_{g} / 300\right)^{-1}$ & 45 \\
\hline 36 & $\mathrm{He}^{+}+\mathrm{O}_{2}^{-} \rightarrow \mathrm{O}_{2}+\mathrm{He}$ & $2 \times 10^{-7}\left(T_{g} / 300\right)^{-1}$ & 45 \\
\hline 37 & $\mathrm{He}^{+}+\mathrm{O}_{3}^{-} \rightarrow \mathrm{O}_{3}+\mathrm{He}$ & $2 \times 10^{-7}\left(T_{g} / 300\right)^{-1}$ & 45 \\
\hline 38 & $H e^{+}+H^{-} \rightarrow H e+H$ & $2.3 \times 10^{-7} \exp \left(T_{g} / 3\right.$ & 48 \\
\hline 39 & $\mathrm{He}^{+}+\mathrm{OH}^{-} \rightarrow \mathrm{He}+\mathrm{OH}$ & $2 \times 10^{-7}\left(T_{g} / 300\right)^{-0}$ & 53 \\
\hline 40 & $\mathrm{He}^{+}+\mathrm{NO}^{-} \rightarrow \mathrm{NO}+\mathrm{He}$ & $2 \times 10$ & 53 \\
\hline 41 & $\mathrm{He}^{+}+\mathrm{N}_{2} \mathrm{O}^{-} \rightarrow \mathrm{N}_{2} \mathrm{O}+\mathrm{He}$ & $T_{g}(300)^{-1}$ & 53 \\
\hline 42 & $\mathrm{He}^{+}+\mathrm{NO}_{2}^{-} \rightarrow \mathrm{NO}_{2}+\mathrm{He}$ & $2 \times 10^{-7}\left(T_{g} / 300\right)^{-1}$ & 53 \\
\hline 43 & $\mathrm{He}^{+}+\mathrm{NO}_{3}^{-} \rightarrow \mathrm{NO}_{3}+\mathrm{He}$ & $2 \times 10^{-7}\left(T_{g} / 300\right)^{-1}$ & 53 \\
\hline 44 & $\mathrm{He}^{+}+\mathrm{O}_{2}^{-} \rightarrow \mathrm{O}+\mathrm{O}+\mathrm{He}$ & & 45 \\
\hline 45 & $\mathrm{He}^{+}+\mathrm{O}_{3}^{-} \rightarrow \mathrm{He}+\mathrm{O}+\mathrm{O}_{2}$ & $1 \times 10^{-7}$ & 53 \\
\hline 46 & $\mathrm{He}^{+}+\mathrm{O}_{4}^{-} \rightarrow \mathrm{He}+2 \mathrm{O}_{2}$ & $1 \times 10^{-7}$ & 53 \\
\hline 47 & $\mathrm{He}^{+}+\mathrm{OH}^{-} \rightarrow \mathrm{He}+\mathrm{O}+\mathrm{H}$ & $1 \times 10^{-7}$ & 53 \\
\hline 48 & $\mathrm{He}^{+}+\mathrm{NO}^{-} \rightarrow \mathrm{N}+\mathrm{O}+\mathrm{He}$ & $1 \times 10^{-7}$ & 53 \\
\hline 49 & $\mathrm{He}^{+}+\mathrm{N}_{2} \mathrm{O}^{-} \rightarrow \mathrm{N}_{2}+\mathrm{O}+\mathrm{He}$ & $1 \times 10^{-7}$ & 53 \\
\hline 50 & $\mathrm{He}^{+}+\mathrm{NO}_{2}^{-} \rightarrow \mathrm{NO}+\mathrm{O}+\mathrm{He}$ & $1 \times 10^{-7}$ & 53 \\
\hline 51 & $\mathrm{He}^{+}+\mathrm{NO}_{3}^{-} \rightarrow \mathrm{NO}+\mathrm{O}_{2}+\mathrm{He}$ & $1 \times 10^{-7}$ & 53 \\
\hline 52 & $\mathrm{He}_{2}^{+}+\mathrm{O}^{-} \rightarrow \mathrm{O}+2 \mathrm{He}$ & $1 \times 10^{-7}$ & 10,53 \\
\hline 53 & $\mathrm{He}_{2}^{+}+\mathrm{O}_{2}^{-} \rightarrow \mathrm{O}_{2}+2 \mathrm{He}$ & $1 \times 10^{-7}$ & 10,53 \\
\hline 54 & $\mathrm{He}_{2}^{+}+\mathrm{O}_{3}^{-} \rightarrow \mathrm{O}_{3}+2 \mathrm{He}$ & $1 \times 10^{-7}$ & 10,53 \\
\hline 55 & $\mathrm{He}_{2}^{+}+\mathrm{H}^{-} \rightarrow \mathrm{H}+2 \mathrm{He}$ & $1 \times 10^{-7}$ & 53 \\
\hline 56 & $\mathrm{He}_{2}^{+}+\mathrm{OH}^{-} \rightarrow \mathrm{OH}+2 \mathrm{He}$ & $1 \times 10^{-7}$ & 53 \\
\hline 57 & $\mathrm{He}_{2}^{+}+\mathrm{NO}^{-} \rightarrow \mathrm{NO}+2 \mathrm{He}$ & $1 \times 10^{-7}$ & 53 \\
\hline 58 & $\mathrm{He}_{2}^{+}+\mathrm{N}_{2} \mathrm{O}^{-} \rightarrow \mathrm{N}_{2} \mathrm{O}+2 \mathrm{He}$ & $1 \times 10^{-7}$ & 53 \\
\hline 59 & $\mathrm{He}_{2}^{+}+\mathrm{NO}_{2}^{-} \rightarrow \mathrm{NO}_{2}+2 \mathrm{He}$ & $1 \times 10^{-7}$ & 53 \\
\hline
\end{tabular}




\begin{tabular}{|c|c|c|c|}
\hline 60 & $\mathrm{He}_{2}^{+}+\mathrm{NO}_{3}^{-} \rightarrow \mathrm{NO}_{3}+2 \mathrm{He}$ & $1 \times 10^{-7}$ & 5 \\
\hline 61 & $\mathrm{HeH}^{+}+\mathrm{O}^{-} \rightarrow \mathrm{OH}+\mathrm{He}$ & $1 \times 10^{-7}$ & \\
\hline 62 & $\mathrm{HeH}^{+}+\mathrm{O}_{2}^{-} \rightarrow \mathrm{HO}_{2}+\mathrm{He}$ & $1 \times 10^{-7}$ & 53 \\
\hline 63 & $\mathrm{HeH}^{+}+\mathrm{O}_{3}^{-} \rightarrow \mathrm{H}+\mathrm{O}_{3}+\mathrm{He}$ & $1 \times 10^{-7}$ & \\
\hline 64 & $\mathrm{HeH}^{+}+\mathrm{H}^{-} \rightarrow \mathrm{H}_{2}+\mathrm{He}$ & $1 \times 10^{-7}$ & 53 \\
\hline 65 & $\mathrm{HeH}^{+}+\mathrm{OH}^{-} \rightarrow \mathrm{H}_{2} \mathrm{O}+2 \mathrm{He}$ & $1 \times 10^{-7}$ & 53 \\
\hline 66 & $\mathrm{HeH}^{+}+\mathrm{NO}^{-} \rightarrow \mathrm{HNO}+\mathrm{He}$ & $1 \times 10^{-7}$ & 53 \\
\hline 67 & $\mathrm{HeH}^{+}+\mathrm{N}_{2} \mathrm{O}^{-} \rightarrow \mathrm{H}+\mathrm{N}_{2} \mathrm{O}+\mathrm{He}$ & $1 \times 10^{-7}$ & 53 \\
\hline 68 & $\mathrm{HeH}^{+}+\mathrm{NO}_{2}^{-} \rightarrow \mathrm{HNO}_{2}+\mathrm{He}$ & $1 \times 10^{-7}$ & 53 \\
\hline 69 & $\mathrm{HeH}^{+}+\mathrm{NO}_{3}^{-} \rightarrow \mathrm{HNO}_{3}+\mathrm{He}$ & $1 \times 10^{-7}$ & 53 \\
\hline 70 & $\mathrm{He}_{2}^{+}+\mathrm{O}_{2}^{-} \rightarrow \mathrm{O}+\mathrm{O}+2 \mathrm{He}$ & $1 \times 10^{-7}$ & 53 \\
\hline 71 & $\mathrm{He}_{2}^{+}+\mathrm{O}_{3}^{-} \rightarrow \mathrm{O}_{2}+\mathrm{O}+2 \mathrm{He}$ & $1 \times 10^{-7}$ & 53 \\
\hline 72 & $\mathrm{He}_{2}^{+}+\mathrm{O}_{4}^{-} \rightarrow 2 \mathrm{O}_{2}+2 \mathrm{He}$ & $1 \times 10^{-7}$ & 53 \\
\hline 73 & $\mathrm{He}_{2}^{+}+\mathrm{OH}^{-} \rightarrow \mathrm{O}+\mathrm{H}+2 \mathrm{He}$ & $10^{-7}$ & 53 \\
\hline 74 & $\mathrm{He}_{2}^{+}+\mathrm{NO}^{-} \rightarrow \mathrm{N}+\mathrm{O}+2 \mathrm{He}$ & $0-7$ & 53 \\
\hline 75 & $\mathrm{He}_{2}^{+}+\mathrm{N}_{2} \mathrm{O}^{-} \rightarrow \mathrm{N}_{2}+\mathrm{O}+2 \mathrm{He}$ & & 53 \\
\hline 76 & $\mathrm{He}_{2}^{+}+\mathrm{NO}_{2}^{-} \rightarrow \mathrm{NO}+\mathrm{O}+2 \mathrm{He}$ & & 53 \\
\hline 77 & $\mathrm{He}_{2}^{+}+\mathrm{NO}_{3}^{-} \rightarrow \mathrm{NO}+\mathrm{O}_{2}+2 \mathrm{He}$ & $1 \times 10^{-7}$ & 53 \\
\hline 78 & $\mathrm{HeH}^{+}+\mathrm{O}_{2}^{-} \rightarrow \mathrm{H}+\mathrm{O}+\mathrm{O}+\mathrm{He}$ & $1 \times 10^{-7}$ & 53 \\
\hline 79 & $\mathrm{HeH}^{+}+\mathrm{O}_{3}^{-} \rightarrow$ & $1 \times 10^{-7}$ & 53 \\
\hline 80 & $\mathrm{HeH}^{+}+\mathrm{O}_{4}^{-}$ & $1 \times 10^{-7}$ & 53 \\
\hline 81 & $\mathrm{HeH}^{+}+\mathrm{OH}^{-}$ & $1 \times 10^{-7}$ & 53 \\
\hline 82 & $\mathrm{HeH}^{+}+\mathrm{NO}^{-}$ & $1 \times 10^{-7}$ & 53 \\
\hline 83 & $\mathrm{HeH}^{+}+\mathrm{N}_{2} \mathrm{O}^{-} \rightarrow \mathrm{H}+\mathrm{N}_{2}+\mathrm{O}+\mathrm{He}$ & $1 \times 10^{-7}$ & 53 \\
\hline 84 & $\mathrm{HeH}^{+}+\mathrm{NO}_{2}^{-} \rightarrow \mathrm{HNO}+\mathrm{O}+\mathrm{He}$ & $1 \times 10^{-7}$ & 53 \\
\hline 85 & $\mathrm{O}_{3} \rightarrow \mathrm{HNO}+\mathrm{O}_{2}+\mathrm{He}$ & $1 \times 10^{-7}$ & 53 \\
\hline \multicolumn{4}{|c|}{ Charge transfer } \\
\hline 86 & & $5.0 \times 10^{-11}\left(T_{g} / 300\right)^{0.5}$ & 45 \\
\hline 87 & $\mathrm{He}^{+}+\mathrm{O}\left({ }^{1} \mathrm{D}\right) \rightarrow \mathrm{O}^{+}+\mathrm{He}$ & $5 \times 10^{-11}\left(T_{g} / 300\right)^{0.5}$ & 45 \\
\hline 88 & $\mathrm{He}^{+}+\mathrm{O}_{2}(\mathrm{a}) \rightarrow \mathrm{O}_{2}^{+}+\mathrm{He}$ & $3.3 \times 10^{-11}\left(T_{g} / 300\right)^{0.5}$ & 45 \\
\hline 89 & $\mathrm{He}^{+}+\mathrm{O}_{2} \rightarrow \mathrm{O}_{2}^{+}+\mathrm{He}$ & $3.3 \times 10^{-11}\left(T_{g} / 300\right)^{0.5}$ & 45 \\
\hline 90 & $\mathrm{He}^{+}+\mathrm{O}_{2} \rightarrow \mathrm{O}^{+}+\mathrm{O}+\mathrm{He}$ & $1.07 \times 10^{-9}\left(T_{g} / 300\right)^{0.5}$ & 45 \\
\hline
\end{tabular}




\begin{tabular}{|c|c|c|c|}
\hline 91 & $\mathrm{He}^{+}+\mathrm{O}_{2}(a) \rightarrow \mathrm{O}^{+}+\mathrm{O}+\mathrm{He}$ & $1.07 \times 10^{-9}\left(T_{g} / 300\right)^{0.5}$ & \\
\hline 92 & $\mathrm{He}^{+}+\mathrm{O}_{3} \rightarrow \mathrm{O}^{+}+\mathrm{O}_{2}+\mathrm{He}$ & $1.07 \times 10^{-9}\left(T_{g} / 300\right)^{0.5}$ & \\
\hline 93 & $\mathrm{He}^{+}+\mathrm{H} \rightarrow \mathrm{He}+\mathrm{H}^{+}$ & $1.9 \times 10^{-15}$ & \\
\hline 94 & $\mathrm{He}^{+}+\mathrm{H} \rightarrow \mathrm{HeH}^{+}$ & $1.58 \times 10^{-15}\left(T_{g} / 300\right)^{-0.3}$ & \\
\hline 95 & $\mathrm{He}^{+}+\mathrm{H}_{2} \rightarrow \mathrm{He}+\mathrm{H}_{2}^{+}$ & $7.2 \times 10^{-15}$ & 48 \\
\hline 96 & $\mathrm{He}^{+}+\mathrm{H}_{2} \rightarrow \mathrm{He}+\mathrm{H}+\mathrm{H}^{+}$ & $3.7 \times 10^{-14} \exp \left(-35 / T_{g}\right)$ & 48 \\
\hline 97 & $\mathrm{He}^{+}+\mathrm{OH} \rightarrow \mathrm{O}^{+}+\mathrm{H}+\mathrm{He}$ & $1.1 \times 10^{-9}$ & 48 \\
\hline 98 & $\mathrm{He}^{+}+\mathrm{H}_{2} \mathrm{O} \rightarrow \mathrm{H}_{2} \mathrm{O}^{+}+\mathrm{He}$ & $6.05 \times 10^{-11}$ & 48 \\
\hline 99 & $\mathrm{He}^{+}+\mathrm{H}_{2} \mathrm{O} \rightarrow \mathrm{H}^{+}+\mathrm{OH}+\mathrm{He}$ & $2.04 \times 10^{-10}$ & 48 \\
\hline 100 & $\mathrm{He}^{+}+\mathrm{H}_{2} \mathrm{O} \rightarrow \mathrm{OH}^{+}+\mathrm{H}+\mathrm{He}$ & $2.86 \times 10^{-10}$ & 48 \\
\hline 101 & $\mathrm{He}^{+}+\mathrm{N}_{2} \rightarrow \mathrm{N}_{2}^{+}+\mathrm{He}$ & $6.0 \times 10^{-10}$ & 49 \\
\hline 102 & $\mathrm{He}^{+}+\mathrm{N}_{2} \rightarrow \mathrm{N}+\mathrm{N}^{+}+\mathrm{He}$ & $6.0 \times 10^{-10}$ & 49 \\
\hline 103 & $\mathrm{He}^{+}+\mathrm{NO} \rightarrow \mathrm{NO}^{+}+\mathrm{He}$ & $1.6 \times 10$ & 55 \\
\hline 104 & $\mathrm{He}^{+}+\mathrm{NO} \rightarrow \mathrm{O}+\mathrm{N}^{+}+\mathrm{He}$ & $1.25 \times 10^{-9}$ & 55 \\
\hline 105 & $\mathrm{He}^{+}+2 \mathrm{He} \rightarrow \mathrm{He}_{2}^{+}+\mathrm{He}$ & $1.4 \times 10^{-31}\left(T_{g} / 300\right)^{-0.6}$ & 69 \\
\hline 106 & $\mathrm{He}_{2}^{+}+\mathrm{O}$ & $1 \times 10^{-9}\left(T_{g} / 300\right)^{0.5}$ & 10 \\
\hline 107 & $\mathrm{He}_{2}^{+}+\mathrm{O}\left({ }^{1} \mathrm{D}\right) \rightarrow \mathrm{O}^{+}+2 \mathrm{He}$ & $1 \times 10^{-9}\left(T_{g} /\right.$ & 10 \\
\hline 108 & $\mathrm{He}_{2}^{+}+\mathrm{O}_{2} \rightarrow \mathrm{O}_{2}^{+}+2 \mathrm{He}$ & $1 \times 10^{-9}\left(T_{g} / 300\right)^{0.5}$ & 10 \\
\hline 109 & $\mathrm{He}_{2}^{+}+$ & $1.05 \times 10^{-9}$ & 56 \\
\hline 110 & $\mathrm{He}_{2}^{+}+$ & $1 \times 10^{-9}\left(T_{g} / 300\right)^{0.5}$ & 10 \\
\hline 111 & $\mathrm{He}_{2}^{+}+\mathrm{O}_{3} \rightarrow \mathrm{O}_{2}+2 \mathrm{He}+\mathrm{O}^{+}$ & $1 \times 10^{-9}\left(T_{g} / 300\right)^{0.5}$ & 10 \\
\hline 112 & $\mathrm{He}_{2}^{+}$ & $1.2 \times 10^{-9}$ & 49 \\
\hline 113 & $e_{2}^{*}+N_{2}^{+}$ & $1.4 \times 10^{-9}$ & 57 \\
\hline 114 & $\mathrm{He}_{2}^{+}+\mathrm{NO} \rightarrow 2 \mathrm{He}+\mathrm{NO}^{+}$ & $1.3 \times 10^{-9}$ & 55 \\
\hline 115 & $H \rightarrow H^{+}+2 H e$ & $3.5 \times 10^{-10}$ & 9 \\
\hline 116 & $\mathrm{He}_{2}{ }^{+}+\mathrm{H}_{2} \rightarrow \mathrm{HeH}^{+}+\mathrm{H}+\mathrm{He}$ & $1.76 \times 10^{-10}$ & 72 \\
\hline 117 & $\mathrm{He}_{2}{ }^{+}+\mathrm{H}_{2} \rightarrow \mathrm{H}_{2}{ }^{+}+2 \mathrm{He}$ & $3.5 \times 10^{-10}$ & 72 \\
\hline 118 & $\mathrm{He}_{2}^{+}+\mathrm{OH} \rightarrow \mathrm{OH}^{+}+2 \mathrm{He}$ & $1.2 \times 10^{-9}$ & 9 \\
\hline 119 & $\mathrm{He}_{2}^{+}+\mathrm{H}_{2} \mathrm{O} \rightarrow \mathrm{O}^{+}+\mathrm{H}_{2}+2 \mathrm{He}$ & $2.1 \times 10^{-10}$ & 58 \\
\hline 120 & $\mathrm{He}_{2}^{+}+\mathrm{H}_{2} \mathrm{O} \rightarrow \mathrm{OH}^{+}+\mathrm{H}+2 \mathrm{He}$ & $2.1 \times 10^{-10}$ & 58 \\
\hline 121 & $\mathrm{He}_{2}^{+}+\mathrm{H}_{2} \mathrm{O} \rightarrow \mathrm{H}^{+}+\mathrm{OH}+2 \mathrm{He}$ & $2.1 \times 10^{-10}$ & 58 \\
\hline
\end{tabular}




\begin{tabular}{|c|c|c|c|}
\hline 122 & $\mathrm{He}_{2}^{+}+\mathrm{H}_{2} \mathrm{O} \rightarrow \mathrm{HeH}^{+}+\mathrm{OH}+\mathrm{He}$ & $1.3 \times 10^{-10}$ & \\
\hline 123 & $\mathrm{He}_{2}^{+}+\mathrm{H}_{2} \mathrm{O} \rightarrow \mathrm{H}_{2}^{+}+\mathrm{O}+2 \mathrm{He}$ & $2.1 \times 10^{-10}$ & \\
\hline 124 & $\mathrm{HeH}^{+}+\mathrm{H} \rightarrow \mathrm{H}_{2}^{+}+\mathrm{He}$ & $9.1 \times 10^{-10}$ & \\
\hline 125 & $\mathrm{HeH}^{+}+\mathrm{H}_{2} \rightarrow \mathrm{H}_{3}^{+}+\mathrm{He}$ & $1.5 \times 10^{-9}$ & \\
\hline 126 & $\mathrm{HeH}^{+}+\mathrm{H}_{2} \mathrm{O} \rightarrow \mathrm{H}_{3} \mathrm{O}^{+}+\mathrm{He}$ & $4.3 \times 10^{-10}$ & 59 \\
\hline 127 & $\mathrm{He}^{*}+\mathrm{He}_{2}^{+} \rightarrow \mathrm{He}^{+}+2 \mathrm{He}$ & $1 \times 10^{-10}$ & 65 \\
\hline 128 & $\mathrm{He}^{*}+\mathrm{O}_{2}^{+} \rightarrow \mathrm{O}+\mathrm{He}+\mathrm{O}^{+}$ & $1.0 \times 10^{-10}$ & 65 \\
\hline 129 & $\mathrm{He}^{*}+\mathrm{O}_{4}^{+} \rightarrow \mathrm{O}_{2}+\mathrm{He}+\mathrm{O}_{2}^{+}$ & $1.0 \times 10^{-10}$ & 65 \\
\hline 130 & $\mathrm{He}^{*}+\mathrm{H}_{2} \mathrm{O}^{+} \rightarrow 2 \mathrm{H}+\mathrm{He}+\mathrm{O}^{+}$ & $1.0 \times 10^{-10}$ & 65 \\
\hline 131 & $\mathrm{He}^{*}+\mathrm{H}_{3} \mathrm{O}^{+} \rightarrow \mathrm{H}+\mathrm{He}+\mathrm{H}_{2} \mathrm{O}^{+}$ & $1.0 \times 10^{-10}$ & 65 \\
\hline 132 & $\mathrm{He}^{*}+\mathrm{N}_{2}^{+} \rightarrow \mathrm{N}+\mathrm{He}+\mathrm{N}^{+}$ & $1.0 \times 10^{-10}$ & 65 \\
\hline 133 & $\mathrm{He}^{*}+\mathrm{N}_{3}^{+} \rightarrow \mathrm{N}+\mathrm{He}+\mathrm{N}_{2}^{+}$ & $1.0 \times 10^{-10}$ & 65 \\
\hline 134 & $\mathrm{He}^{*}+\mathrm{N}_{4}^{+} \rightarrow \mathrm{N}_{2}+\mathrm{He}+\mathrm{N}_{2}^{+}$ & $1.0 \times 10^{-10}$ & 65 \\
\hline 135 & $\mathrm{He}^{*}+\mathrm{NO}^{+} \rightarrow \mathrm{O}+\mathrm{He}+\mathrm{N}^{+}$ & $5.0 \times 10^{-11}$ & 65 \\
\hline 136 & $\mathrm{He}^{*}+\mathrm{NO}^{+} \rightarrow \mathrm{N}+\mathrm{He}+\mathrm{O}^{+}$ & $5.0 \times 10^{-11}$ & 65 \\
\hline 137 & $\mathrm{He}_{2}{ }^{*}+\mathrm{O}_{2}^{+} \rightarrow \mathrm{O}+2 \mathrm{He}+\mathrm{O}^{+}$ & 1 & 65 \\
\hline 138 & $\mathrm{He}_{2}{ }^{*}+\mathrm{O}_{4}^{+} \rightarrow \mathrm{O}_{2}+2 \mathrm{He}+\mathrm{O}_{2}^{+}$ & $1 \times 10^{-10}$ & 65 \\
\hline 139 & $\mathrm{He}_{2}{ }^{*}+\mathrm{H}_{3} \mathrm{O}^{+} \rightarrow \mathrm{H}+2 \mathrm{He}+\mathrm{H}_{2} \mathrm{O}^{+}$ & $1.0 \times 10^{-10}$ & 65 \\
\hline 140 & $\mathrm{He}_{2}{ }^{*}+\mathrm{H}_{3} \mathrm{O}^{+} \rightarrow 3 \mathrm{H}+2 \mathrm{He}+\mathrm{O}^{+}$ & $1.0 \times 10^{-10}$ & 65 \\
\hline 141 & $\mathrm{He}_{2}{ }^{*}+\mathrm{N}_{3}^{+} \rightarrow 1$ & $1.0 \times 10^{-10}$ & 65 \\
\hline 142 & $\mathrm{He}_{2}{ }^{*}+\mathrm{N}_{4}^{+}-$ & $1.0 \times 10^{-10}$ & 65 \\
\hline 143 & $H e^{*}+2 H$ & $1.5 \times 10^{-34}$ & 78 \\
\hline 144 & $H e+H^{+}$ & $8.4 \times 10^{-19}\left(T_{g} / 300\right)^{-4.5}$ & 60 \\
\hline 145 & $\mathrm{He}+\mathrm{H}_{2}^{+}$ & $1.3 \times 10^{-10}$ & 48 \\
\hline 146 & & $1.1 \times 10^{-30}\left(T_{g} / 300\right)^{-1}$ & 49 \\
\hline 147 & $\mathrm{He}+\mathrm{O}^{-}+\mathrm{NO} \rightarrow \mathrm{He}+\mathrm{NO}_{2}^{-}$ & $4.0 \times 10^{-31}$ & 56 \\
\hline 148 & $+\mathrm{O}_{2} \rightarrow \mathrm{He}+\mathrm{O}_{4}^{-}$ & $3.5 \times 10^{-31}\left(T_{g} / 300\right)^{-1}$ & 49 \\
\hline 149 & $\mathrm{He}+\mathrm{O}^{+}+\mathrm{O} \rightarrow \mathrm{He}+\mathrm{O}_{2}^{+}$ & $1 \times 10^{-29}\left(T_{g} / 300\right)^{0.5}$ & 45 \\
\hline 150 & $\mathrm{He}+\mathrm{O}^{+}+\mathrm{N} \rightarrow \mathrm{He}+\mathrm{NO}^{+}$ & $1 \times 10^{-29}$ & 51 \\
\hline 151 & $\mathrm{He}+\mathrm{O}^{+}+\mathrm{N}_{2} \rightarrow \mathrm{He}+\mathrm{NO}^{+}+\mathrm{N}$ & $6 \times 10^{-29}\left(T_{g} / 300\right)^{-2}$ & 49 \\
\hline 152 & $\mathrm{He}+\mathrm{O}_{2}^{+}+\mathrm{O}_{2} \rightarrow \mathrm{He}+\mathrm{O}_{4}^{+}$ & $3.9 \times 10^{-30}\left(T_{g} / 300\right)^{-3.2}$ & 49 \\
\hline 153 & $\mathrm{He}+\mathrm{N}^{+}+\mathrm{O} \rightarrow \mathrm{He}+\mathrm{NO}^{+}$ & $1 \times 10^{-29}$ & 61 \\
\hline
\end{tabular}




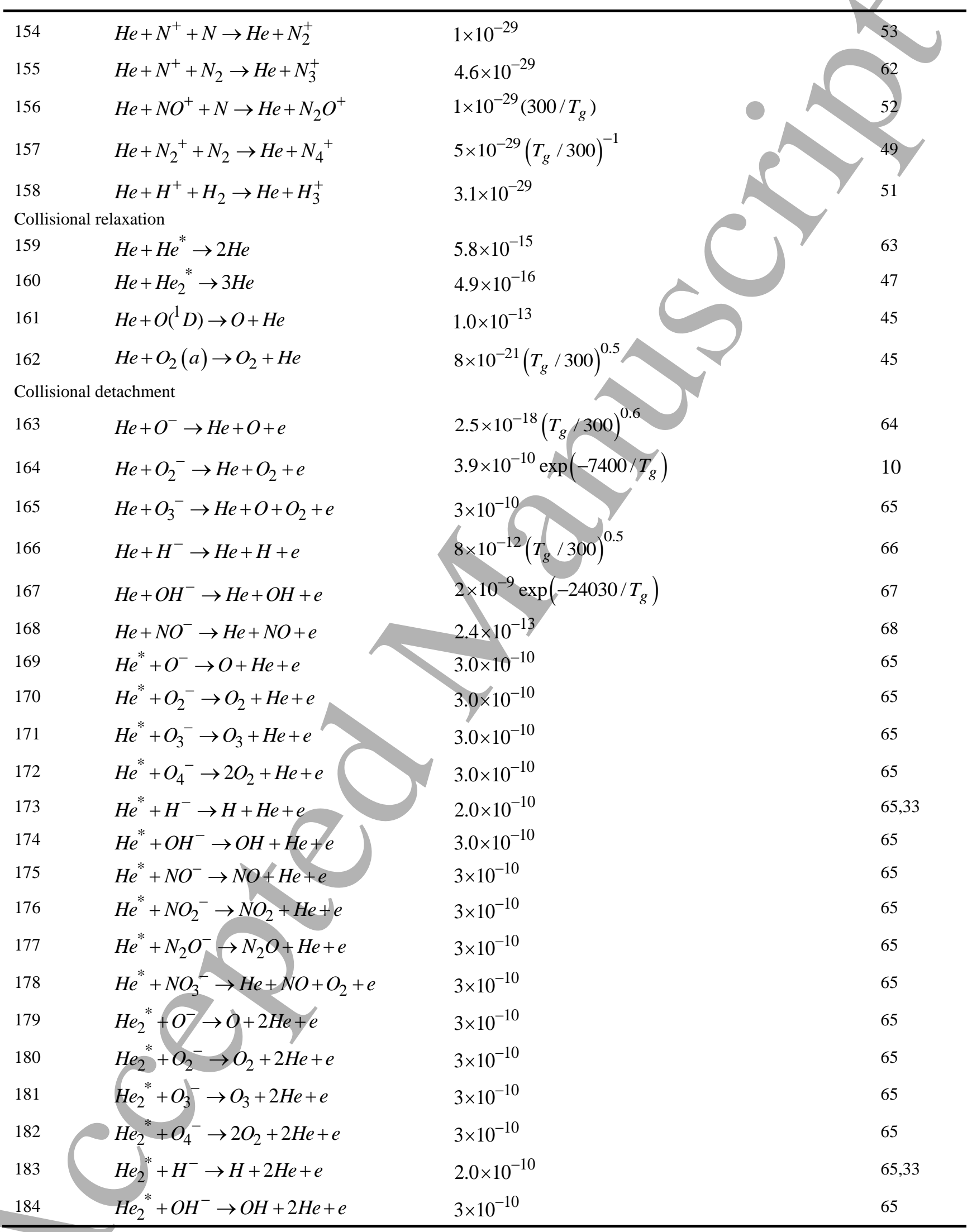




\begin{tabular}{|c|c|c|c|}
\hline 185 & $\mathrm{He}_{2}^{*}+\mathrm{NO}^{-} \rightarrow \mathrm{NO}+2 \mathrm{He}+e$ & $3 \times 10^{-10}$ & \\
\hline 186 & $\mathrm{He}_{2}^{*}+\mathrm{NO}_{2}^{-} \rightarrow \mathrm{NO}_{2}+2 \mathrm{He}+e$ & $3 \times 10^{-10}$ & \\
\hline 187 & $\mathrm{He}_{2}^{*}+\mathrm{N}_{2} \mathrm{O}^{-} \rightarrow \mathrm{N}_{2} \mathrm{O}+2 \mathrm{He}+e$ & $3 \times 10^{-10}$ & 65 \\
\hline 188 & $\mathrm{He}_{2}^{*}+\mathrm{NO}_{3}^{-} \rightarrow 2 \mathrm{He}+\mathrm{NO}+\mathrm{O}_{2}+e$ & $3 \times 10^{-10}$ & \\
\hline \multicolumn{4}{|c|}{ Penning ionization } \\
\hline 189 & $2 \mathrm{He}^{*} \rightarrow \mathrm{He}_{2}^{+}+e$ & $2.03 \times 10^{-9}\left(T_{g} / 300\right)^{0.5}$ & 69 \\
\hline 190 & $2 \mathrm{He}^{*} \rightarrow \mathrm{He}^{+}+\mathrm{He}+e$ & $8.7 \times 10^{-10}\left(T_{g} / 300\right)^{0.5}$ & 69 \\
\hline 191 & $H e^{*}+\mathrm{He}_{2}^{*} \rightarrow \mathrm{He}^{+}+2 \mathrm{He}+e$ & $5 \times 10^{-10}$ & 78 \\
\hline 192 & $\mathrm{He}^{*}+\mathrm{He}_{2}^{*} \rightarrow \mathrm{He}_{2}^{+}+\mathrm{He}+e$ & $2 \times 10^{-9}$ & 78 \\
\hline 193 & $2 \mathrm{He}_{2}^{*} \rightarrow \mathrm{He}^{+}+3 \mathrm{He}+e$ & $3 \times 10^{-10}$ & 78 \\
\hline 194 & $2 \mathrm{He}_{2}^{*} \rightarrow \mathrm{He}_{2}^{+}+2 \mathrm{He}+e$ & $1.2 \times 10^{-9}$ & 50 \\
\hline 195 & $H e^{*}+O\left({ }^{1} D\right) \rightarrow O^{+}+\mathrm{He}+e$ & $3.96 \times 10^{-10}\left(T_{g} / 300\right)^{0.17}$ & 70 \\
\hline 196 & $H e^{*}+\mathrm{O} \rightarrow \mathrm{O}^{+}+\mathrm{He}+e$ & $3.96 \times 10^{-10}\left(T_{g} / 300\right)^{0.17}$ & 70 \\
\hline 197 & $\mathrm{He}^{*}+\mathrm{O}_{2} \rightarrow \mathrm{O}_{2}^{+}+\mathrm{He}+e$ & $2.54 \times 10^{-10}\left(T_{g} / 300\right)^{0.5}$ & 45 \\
\hline 198 & $\mathrm{He}^{*}+\mathrm{O}_{3} \rightarrow \mathrm{O}_{2}^{+}+\mathrm{O}+\mathrm{He}+e$ & $2.6 \times 10^{-10}$ & 78 \\
\hline 199 & $H e^{*}+H \rightarrow H^{+}+H e+e$ & $1.1 \times 10^{-9}$ & 71 \\
\hline 200 & $\mathrm{He}^{*}+\mathrm{H}_{2} \rightarrow \mathrm{H}_{2}^{+}+\mathrm{He}+e$ & $2.9 \times 10^{-11}$ & 72,73 \\
\hline 201 & $\mathrm{He}^{*}+\mathrm{H}_{2} \rightarrow \mathrm{H}+\mathrm{HeH}^{+}+e$ & $3 \times 10^{-12}$ & 72,73 \\
\hline 202 & $\mathrm{He}^{*}+\mathrm{OH} \rightarrow \mathrm{OH}^{+}+\mathrm{He}+e$ & $7.8 \times 10^{-10}$ & 9 \\
\hline 203 & $\mathrm{He}^{*}+\mathrm{H}_{2} \mathrm{O} \rightarrow$ & $6.6 \times 10^{-10}$ & 59 \\
\hline 204 & $\mathrm{He}+\mathrm{OH}^{+}+\mathrm{H}+e$ & $1.5 \times 10^{-10}$ & 74,59 \\
\hline 205 & $\mathrm{He}^{*}+\mathrm{H}_{2} \mathrm{O} \rightarrow \mathrm{He}+\mathrm{OH}+\mathrm{H}^{+}+e$ & $2.6 \times 10^{-11}$ & 74,59 \\
\hline 206 & $\mathrm{He}^{*}+\mathrm{H}_{2} \mathrm{O} \rightarrow \mathrm{HeH}^{+}+\mathrm{OH}+e$ & $8.5 \times 10^{-12}$ & 74,59 \\
\hline 207 & $\mathrm{He}^{*}+\mathrm{H}_{2} \mathrm{O}_{2} \rightarrow \mathrm{He}+\mathrm{OH}^{+}+\mathrm{OH}+e$ & $7.8 \times 10^{-10}$ & 9 \\
\hline 208 & $\mathrm{He}^{*}+\mathrm{N}_{2} \rightarrow \mathrm{N}^{+}+\mathrm{N}+\mathrm{He}+e$ & $1 \times 10^{-10}$ & 65 \\
\hline 209 & $\mathrm{He}^{*}+\mathrm{N}_{2} \rightarrow \mathrm{N}_{2}^{+}+\mathrm{He}+e$ & $5 \times 10^{-11}$ & 47 \\
\hline 210 & $\mathrm{He}_{2}{ }^{*}+\mathrm{O} \rightarrow 2 \mathrm{He}+\mathrm{O}^{+}+e$ & $3.6 \times 10^{-10}$ & 78 \\
\hline 211 & $\mathrm{He}_{2}{ }^{*}+\mathrm{O}\left({ }^{1} \mathrm{D}\right) \rightarrow 2 \mathrm{He}+\mathrm{O}^{+}+e$ & $3.6 \times 10^{-10}$ & 78 \\
\hline 212 & $\mathrm{He}_{2}{ }^{*}+\mathrm{O}_{2} \rightarrow 2 \mathrm{He}+\mathrm{O}_{2}^{+}+e$ & $3.6 \times 10^{-10}$ & 78 \\
\hline 213 & $\mathrm{He}_{2}{ }^{*}+\mathrm{O}_{3} \rightarrow 2 \mathrm{He}+\mathrm{O}_{2}^{+}+\mathrm{O}+e$ & $3.6 \times 10^{-10}$ & 78 \\
\hline 214 & $H e_{2}^{*}+H \rightarrow 2 \mathrm{He}+H^{+}+e$ & $2.2 \times 10^{-10}$ & 9 \\
\hline 215 & $\mathrm{He}_{2}^{*}+\mathrm{H}_{2} \rightarrow \mathrm{H}_{2}^{+}+2 \mathrm{He}+e$ & $2.2 \times 10^{-10}$ & 75 \\
\hline
\end{tabular}




\begin{tabular}{|c|c|c|c|}
\hline 216 & $\mathrm{He}_{2}^{*}+\mathrm{OH} \rightarrow \mathrm{OH}^{+}+2 \mathrm{He}+e$ & $6 \times 10^{-10}$ & , \\
\hline 217 & $\mathrm{He}_{2}^{*}+\mathrm{H}_{2} \mathrm{O} \rightarrow \mathrm{H}_{2} \mathrm{O}^{+}+2 \mathrm{He}+e$ & $6 \times 10^{-10}$ & \\
\hline 218 & $\mathrm{He}_{2}{ }^{*}+\mathrm{H}_{2} \mathrm{O}_{2} \rightarrow \mathrm{OH}^{+}+\mathrm{OH}+2 \mathrm{He}+e$ & $6 \times 10^{-10}$ & 9 \\
\hline 219 & $\mathrm{He}_{2}{ }^{*}+\mathrm{N}_{2} \rightarrow 2 \mathrm{He}+\mathrm{N}_{2}^{+}+e$ & $3 \times 10^{-11}$ & \\
\hline \multicolumn{4}{|c|}{ Neutral reactions } \\
\hline 220 & $\mathrm{He}+\mathrm{O}_{3} \rightarrow \mathrm{He}+\mathrm{O}+\mathrm{O}_{2}$ & $1.56 \times 10^{-9} \exp \left(-11400 / T_{g}\right)$ & 78,45 \\
\hline 221 & $\mathrm{He}+2 \mathrm{O} \rightarrow \mathrm{He}+\mathrm{O}_{2}$ & $1.3 \times 10^{-32}\left(T_{g} / 300\right)^{-1} \exp \left(-170 / T_{g}\right)$ & 45 \\
\hline 222 & $\mathrm{He}+\mathrm{O}_{2}+\mathrm{O} \rightarrow \mathrm{He}+\mathrm{O}_{3}$ & $3.4 \times 10^{-34}\left(T_{g} / 300\right)^{-}$ & 45 \\
\hline 223 & $\mathrm{He}+\mathrm{N}+\mathrm{O} \rightarrow \mathrm{He}+\mathrm{NO}$ & $1.76 \times 10^{-31} T_{g}^{-0.5}$ & 72 \\
\hline 224 & $\mathrm{He}+\mathrm{NO}+\mathrm{O} \rightarrow \mathrm{He}+\mathrm{NO}_{2}$ & $1 \times 10^{-31}$ & 79 \\
\hline 225 & $\mathrm{He}+\mathrm{N}+\mathrm{N} \rightarrow \mathrm{He}+\mathrm{N}_{2}$ & $7.6 \times 10^{-34} \exp \left(500 / T_{g}\right)$ & 65 \\
\hline 226 & $\mathrm{He}+\mathrm{H}+\mathrm{O} \rightarrow \mathrm{He}+\mathrm{OH}$ & $3.2 \times 10^{-33}\left(T_{g} / 300\right)^{-1}$ & 10 \\
\hline 227 & $\mathrm{He}+\mathrm{H}+\mathrm{OH} \rightarrow \mathrm{He}+\mathrm{H}_{2} \mathrm{O}$ & $1.56 \times 10^{-31}\left(T_{g} / 300\right)^{-2.6}$ & 9,80 \\
\hline 228 & $\mathrm{He}+2 \mathrm{H} \rightarrow \mathrm{He}+\mathrm{H}_{2}$ & $5.8 \times 10^{-33}\left(T_{g} / 300\right)^{-1}$ & 81 \\
\hline 229 & $\mathrm{He}+\mathrm{H}+\mathrm{O}_{2} \rightarrow \mathrm{He}+\mathrm{HO}_{2}$ & $2 \times 10^{-32}\left(T_{g} / 300\right)^{-0.8}$ & 81 \\
\hline 230 & $\mathrm{He}+2 \mathrm{OH} \rightarrow \mathrm{He}+\mathrm{H}_{2} \mathrm{O}_{2}$ & $10^{-31}\left(T_{g} / 300\right)^{-3.2}$ & 81 \\
\hline 231 & $\mathrm{He}+2 \mathrm{O} \rightarrow \mathrm{O}_{2}(\mathrm{a}$ & $9.88 \times 10^{-35}$ & 45 \\
\hline 232 & $\mathrm{He}+\mathrm{O}+\mathrm{I}$ & $9 \times 10^{-32}\left(300 / T_{g}\right)^{2}$ & 82 \\
\hline 233 & $\mathrm{He}+O\left({ }^{1} \mathrm{~L}\right.$ & $9 \times 10^{-37}$ & 83 \\
\hline 234 & $\mathrm{He}+\mathrm{N}$ & $3.09 \times 10^{-34}\left(300 / T_{g}\right)^{7.7}$ & 84 \\
\hline 235 & $\mathrm{He}+\mathrm{NO}$ & $7.4 \times 10^{-31}\left(300 / T_{g}\right)^{2.4}$ & 82 \\
\hline 236 & $\mathrm{He}+\mathrm{NO}$ & $1 \times 10^{-32} \exp \left(300 / T_{g}\right)$ & 85 \\
\hline 237 & $\mathrm{He}+\mathrm{NO}_{2}+\mathrm{NO}_{2} \rightarrow \mathrm{He}+\mathrm{N}_{2} \mathrm{O}_{4}$ & $1.17 \times 10^{-33}\left(300 / T_{g}\right)^{3.8}$ & 84 \\
\hline 238 & $\mathrm{He}+\mathrm{NO}_{2}+\mathrm{NO}_{3} \rightarrow \mathrm{He}+\mathrm{N}_{2} \mathrm{O}_{5}$ & $2.8 \times 10^{-30}\left(300 / T_{g}\right)^{3.5}$ & 83 \\
\hline 239 & $\mathrm{He}+\mathrm{NO}_{2}+\mathrm{OH} \rightarrow \mathrm{He}+\mathrm{HNO}_{3}$ & $2.2 \times 10^{-30}\left(300 / T_{g}\right)^{2.9}$ & 82 \\
\hline 240 & $\mathrm{He}+\mathrm{N}_{2} \mathrm{O}_{3} \rightarrow \mathrm{He}+\mathrm{NO}+\mathrm{NO}_{2}$ & $1.03 \times 10^{-10} \exp \left(-2628 / T_{g}\right)$ & 84 \\
\hline 241 & $\mathrm{He}+\mathrm{N}_{2} \mathrm{O}_{4} \rightarrow \mathrm{He}+\mathrm{NO}_{2}+\mathrm{NO}_{2}$ & $1.09 \times 10^{-7} \exp \left(-4952 / T_{g}\right)$ & 84 \\
\hline 242 & $\mathrm{He}+\mathrm{N}_{2} \mathrm{O}_{5} \rightarrow \mathrm{He}+\mathrm{NO}_{2}+\mathrm{NO}_{3}$ & $1 \times 10^{-3}\left(300 / T_{g}\right)^{3.5} \exp \left(-11000 / T_{g}\right)$ & 83 \\
\hline
\end{tabular}

$\mathrm{T}_{\mathrm{e}}$ in $\mathrm{eV}, \mathrm{T}_{\mathrm{g}}$ in Kelvin

a The rate coefficient is obtained from EEDF using cross section from indicated reference.

${ }^{\mathrm{b}}$ Rate coefficient is in $\mathrm{cm}^{3} / \mathrm{s}$ for two-body reactions and $\mathrm{cm}^{6} / \mathrm{s}$ for three-body reactions 
1

2

3

4

5

6

7

8

9

10

11

12

13

14

15

16

17

18

19

20

21

22

23

24

25

26

27

28

29

30

31

32

33

34

35

36

37

38

39

40

41

42

43

44

45

46

47

48

49

50

51

52

53

54

55

56

57

58

59

60

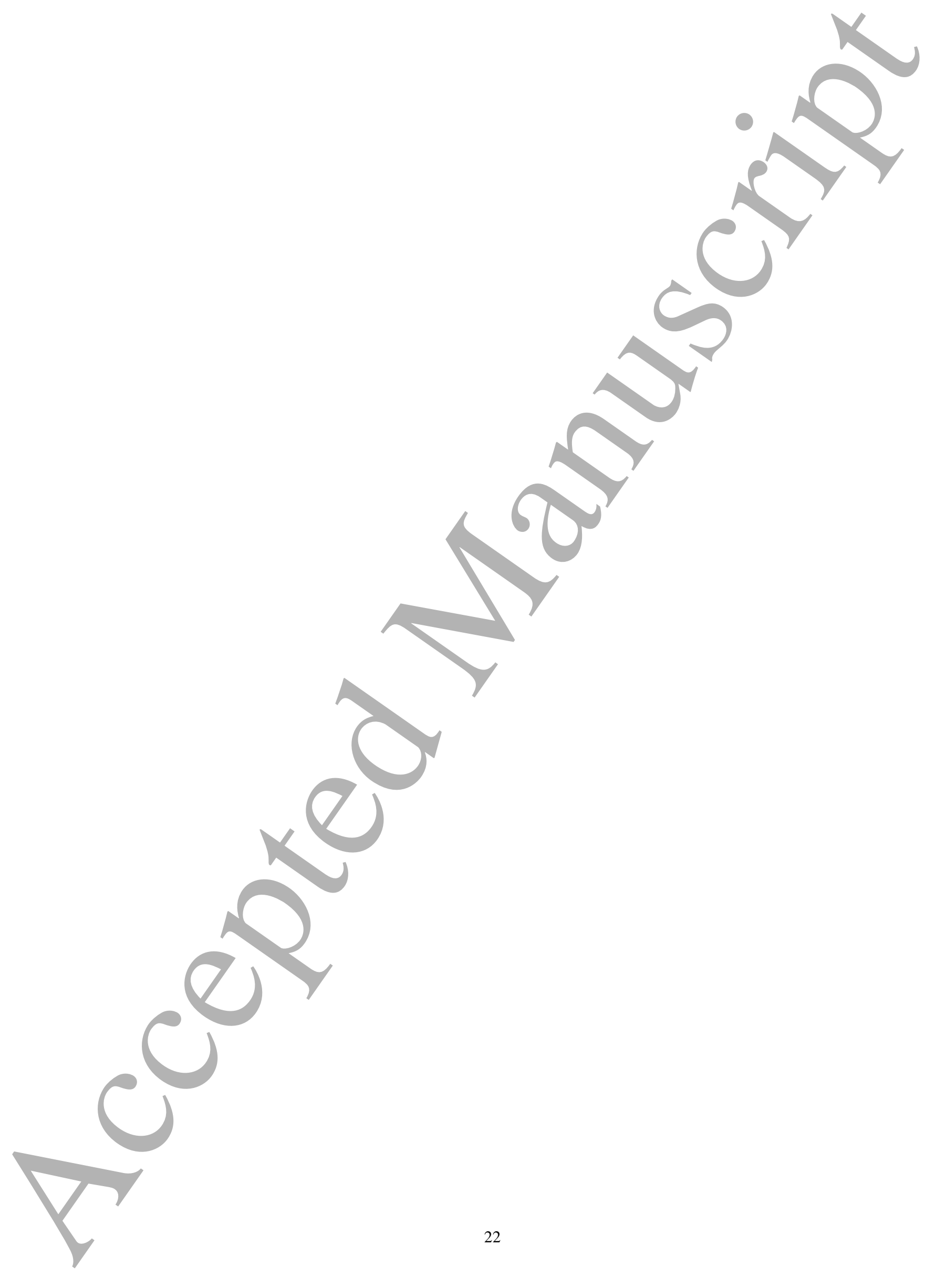




\section{Appendix II : Sidewise loss of neutral species}

The mass conservation for neutral species $i$ is given by the following equation [32]:

$$
\frac{d n_{i}(r, \varphi, z, t)}{d t}-D_{i} \nabla^{2} n_{i}(r, \varphi, z, t)=S_{i}(r, \varphi, z, t)
$$

We are interested in the steady state solution and for simplicity we consider a 1-dimension problem in $r$. In this case, $\mathrm{A} 1$ reduces to:

$$
-\frac{D}{r} \frac{d}{d r}\left(r \frac{d n}{d r}\right)=G-K n
$$

where $G$ is the average generation rate due to gas phase reactions (assumed to be constant) and $K$ the reaction frequency for the destruction of species $i$ (assuming a linear approximation).

To solve A2, we assume as boundary condition that the flux at $r=R$ is the thermal flux:

$$
-\left.D \frac{d n}{d r}\right|_{r=R}=0.25 n(R) v_{t h}
$$

The solution to A2 will be the sum of solution to the homogeneous equation and a particular solution. A particular solution to $\mathrm{A} 2$ is:

$$
n_{p}=\frac{G}{K}
$$

And the homogeneous equation can be re-written as follows:

$$
\begin{aligned}
& \frac{d^{2} n}{d r^{2}}+\frac{1}{r} \frac{d n}{d r}-\frac{K}{D} n=0 \Rightarrow \\
& \frac{d^{2} n}{d\left(\sqrt{\frac{K}{D}} r\right)^{2}}+\frac{1}{\sqrt{\frac{K}{D}} r d\left(\sqrt{\frac{K}{D}} r\right)}-n=0
\end{aligned}
$$

The solution of this homogeneous equation is:

$$
n_{h}=A I_{0}\left(\sqrt{\frac{K}{D}} r\right)+B K_{0}\left(\sqrt{\frac{K}{D}} r\right)
$$

where $I_{0}$ is the modified zero-order Bessel function of the first kind and $K_{0}$ the modified zero-order Bessel function of the second kind. A and B are integration constants.
Since $K_{0}(\sqrt{K / D} r)$ diverges at $\mathrm{r}=0$, B must be 0 for a physical solution.

Therefore the solution to Eq. A2 is

$n(r)=n_{p}+n_{h}=\frac{G}{K}+A I_{0}\left(\sqrt{\frac{K}{D}} r\right)$

To determine the integration constant $\mathrm{A}$, we impose the boundary condition $\mathrm{A} 3$ :

$$
\begin{aligned}
& -\left.D \frac{d n}{d r}\right|_{r=R}=-\left.D A I_{0}^{\prime}\left(\sqrt{\frac{K}{D}} r\right)\right|_{r=R} \\
& =-D A \sum_{m=1}^{2 m\left(\sqrt{\frac{K}{D}}\right)^{2 m} R^{2 m-1}} 2^{2 m}(m !)^{2} \\
& =-\sqrt{D K} A \sum_{m=1}^{2 m} \frac{2 m\left(\sqrt{\frac{K}{D}} R\right)^{2 m-1}}{2^{2 m}(m !)^{2}}=0.25\left(\frac{G}{K}+A I_{0}\left(\sqrt{\frac{K}{D}} R\right)\right) v_{t h}
\end{aligned}
$$

And therefore the integration constant $\mathrm{A}$ is equal to:

$$
A=-\frac{0.25 \frac{G}{K} v_{t h}}{\sqrt{D K} \sum_{m=1} \frac{2 m\left(\sqrt{\frac{K}{D}} R\right)^{2 m-1}}{2^{2 m}(m !)^{2}}+0.25 I_{0}\left(\sqrt{\frac{K}{D}} R\right) v_{t h}}
$$

Substituting A9 into A7, we obtain the solution to Eq. A2, i.e. the radial variation of the density for species $i$ :

$$
n(r)=\frac{G}{K}\left(1-\frac{0.25 v_{t h} I_{0}\left(\sqrt{\frac{K}{D}} r\right)}{\sqrt{D K} \sum_{m=1} \frac{2 m\left(\sqrt{\frac{K}{D}} R\right)^{2 m-1}}{2^{2 m}(m !)^{2}}+0.25 I_{0}\left(\sqrt{\frac{K}{D}} R\right) v_{t h}}\right)
$$


The average density of species $\mathrm{i}$ across the radial direction $\left(\mathrm{n}_{\mathrm{ave}}\right)$ is calculated by integrating Eq.A10 and then dividing the result by the electrode disk area. And then the ratio of the boundary density to the average density for species $i$ is given by:

$$
\frac{n(R)}{n_{\text {ave }}}=\frac{R^{2} \sqrt{D K} \sum_{m=1} \frac{2 m\left(\sqrt{\frac{K}{D}} R\right)^{2 m-1}}{2^{2 m}(m !)^{2}}}{\int_{0}^{R} 2 r\left(\sqrt{D K} \sum_{m=1} \frac{2 m\left(\sqrt{\frac{K}{D}} R\right)^{2 m-1}}{2^{2 m}(m !)^{2}}+0.25 I_{0}\left(\sqrt{\frac{K}{D}} R\right) v_{t h}-0.25 v_{t h} I_{0}\left(\sqrt{\frac{K}{D}} r\right)\right.} d r
$$

The radial diffusion loss rate for species $i$ is:

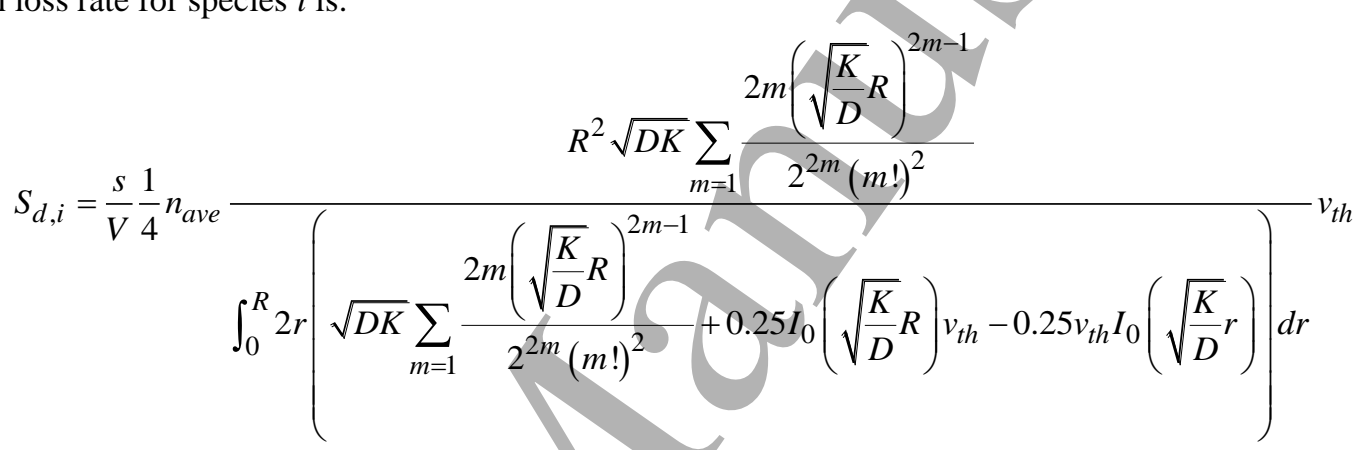




\section{Appendix III: main reactions for $\mathrm{He}+\mathrm{Air}$ plasmas}

\begin{tabular}{|c|c|c|c|}
\hline No. & Reaction & Rate coefficient ${ }^{\mathrm{b}}$ & Ref. \\
\hline \multicolumn{4}{|c|}{ Electron impact momentum transfer } \\
\hline 1 & $e+\mathrm{He} \rightarrow e+\mathrm{He}$ & $f\left(T_{e}\right)$ & \\
\hline \multicolumn{4}{|c|}{ Electron impact excitation and de-excitation } \\
\hline 2 & $e+N \rightarrow N\left({ }^{2} D\right)+e$ & $f\left(T_{e}\right)$ & \\
\hline 3 & $e+N_{2} \rightarrow N_{2}(A)+e$ & $f\left(T_{e}\right)$ & $87^{\mathrm{a}}$ \\
\hline 4 & $e+N_{2} \rightarrow N_{2}(B)+e$ & $f\left(T_{e}\right)$ & $87^{\mathrm{a}}$ \\
\hline 5 & $e+N_{2} \rightarrow N\left({ }^{2} D\right)+N+e$ & $f\left(T_{e}\right)$ & $34^{\mathrm{a}}$ \\
\hline 6 & $e+O \rightarrow O\left({ }^{1} D\right)+e$ & $f\left(T_{e}\right)$ & $88^{\mathrm{a}}$ \\
\hline 7 & $e+O_{2} \rightarrow O_{2}(a)+e$ & $f\left(T_{e}\right)$ & $35^{\mathrm{a}}$ \\
\hline 8 & $e+O_{2} \rightarrow O\left({ }^{1} D\right)+O+e$ & $f\left(T_{e}\right)$ & $89^{\mathrm{a}}$ \\
\hline 9 & $e+\mathrm{H}_{2} \mathrm{O} \rightarrow \mathrm{H}_{2}+O\left({ }^{1} \mathrm{D}\right)+e$ & $f\left(T_{e}\right)$ & $90^{\mathrm{a}}$ \\
\hline 10 & $e+H e \rightarrow e+H e^{*}$ & $f\left(T_{e}\right)$ & $9^{\mathrm{a}}$ \\
\hline \multicolumn{4}{|c|}{ Electron impact dissociation } \\
\hline 11 & $e+\mathrm{H}_{2} \mathrm{O} \rightarrow \mathrm{OH}+\mathrm{H}+e$ & $\left(T_{e}\right)$ & $91^{\mathrm{a}}$ \\
\hline 12 & $e+O_{3} \rightarrow O+O_{2}+e$ & & $92^{\mathrm{a}}$ \\
\hline \multicolumn{4}{|c|}{ Electron impact attachment } \\
\hline 13 & $e+O_{2} \rightarrow O_{2}^{-}$ & & $93^{\mathrm{a}}$ \\
\hline 14 & $e+O_{2} \rightarrow O^{-}+O$ & & $94^{\mathrm{a}}$ \\
\hline 15 & $e+O_{3} \rightarrow O_{2}^{-}+O$ & & $95^{\mathrm{a}}$ \\
\hline 16 & $e+O_{3} \rightarrow O_{2}+O^{-}$ & $f($ & $95^{\mathrm{a}}$ \\
\hline 17 & $e+\mathrm{H}_{2} \mathrm{O} \rightarrow \mathrm{H}^{-}+\mathrm{OH}$ & $f\left(T_{e}\right)$ & $96^{\mathrm{a}}$ \\
\hline 18 & $e+\mathrm{HNO}_{3} \rightarrow \mathrm{NO}_{2}^{-}+\mathrm{OH}$ & $5 \times 10^{-8}$ & 97 \\
\hline 19 & $e+\mathrm{NO}+\mathrm{He} \rightarrow \mathrm{NO}^{-}+$ & $8 \times 10^{-31}$ & 51 \\
\hline \multicolumn{4}{|c|}{ Ion-ion recombination } \\
\hline 20 & $\mathrm{NO}^{+}$ & $2 \times 10^{-7} \times\left(300 / T_{g}\right)^{0.5}$ & 53 \\
\hline 21 & $\mathrm{NO}_{2}^{+}+\mathrm{NO}_{3}^{-} \rightarrow \mathrm{NO}_{3}+\mathrm{NO}$ & $2 \times 10^{-7} \times\left(300 / T_{g}\right)^{0.5}$ & 97 \\
\hline \multicolumn{4}{|c|}{ Charge transfer } \\
\hline 22 & $\mathrm{~N}_{2}^{+}+\mathrm{H}_{2} \mathrm{O} \rightarrow \mathrm{H}_{2} \mathrm{O}^{+}+\mathrm{N}_{2}$ & $2.3 \times 10^{-9}$ & 51 \\
\hline 23 & $\mathrm{O}_{2}^{+}+\mathrm{N}+\mathrm{N}_{2}$ & $2.3 \times 10^{-11}$ & 51 \\
\hline 24 & $\mathrm{~N}_{3}^{+}+\mathrm{O}_{2} \rightarrow \mathrm{NO}^{+}+\mathrm{O}+\mathrm{N}_{2}$ & $2 \times 10^{-11}$ & 51 \\
\hline 25 & $\mathrm{~N}_{3}^{+}+\mathrm{O}_{2} \rightarrow \mathrm{NO}_{2}^{+}+\mathrm{N}_{2}$ & $4.4 \times 10^{-11}$ & 51 \\
\hline 26 & $N_{2} \rightarrow N_{2}^{+}+2 N_{2}$ & $2.1 \times 10^{-10} \times \exp \left(T_{g} / 121\right)$ & 51 \\
\hline 27 & $\mathrm{~N}_{4}^{+}+\mathrm{H}_{2} \mathrm{O} \rightarrow \mathrm{H}_{2} \mathrm{O}^{+}+2 \mathrm{~N}_{2}$ & $3 \times 10^{-9}$ & 51 \\
\hline 28 & $\mathrm{O}_{2}^{+}+\mathrm{N}_{2} \mathrm{O}_{5} \rightarrow \mathrm{NO}_{2}^{+}+\mathrm{NO}$ & $8.8 \times 10^{-10}$ & 53 \\
\hline & $\mathrm{O}_{4}^{+}+\mathrm{O} \rightarrow \mathrm{O}_{2}^{+}+\mathrm{O}_{3}$ & $3 \times 10^{-10}$ & 53 \\
\hline
\end{tabular}




\begin{tabular}{|c|c|c|c|}
\hline 30 & $\mathrm{O}_{4}^{+}+\mathrm{NO} \rightarrow \mathrm{NO}^{+}+2 \mathrm{O}_{2}$ & $6.8 \times 10^{-10}$ & \\
\hline 31 & $\mathrm{NO}^{+}+\mathrm{N}_{2} \mathrm{O}_{5} \rightarrow \mathrm{NO}_{2}^{+}+2 \mathrm{NO}_{2}$ & $5.9 \times 10^{-10}$ & \\
\hline 32 & $\mathrm{NO}_{2}^{+}+\mathrm{NO} \rightarrow \mathrm{NO}^{+}+\mathrm{NO}_{2}$ & $2.75 \times 10^{-10}$ & \\
\hline 33 & $\mathrm{OH}^{+}+\mathrm{O}_{2} \rightarrow \mathrm{O}_{2}^{+}+\mathrm{OH}$ & $5.9 \times 10^{-10}$ & \\
\hline 34 & $\mathrm{H}_{2} \mathrm{O}^{+}+\mathrm{O}_{2} \rightarrow \mathrm{O}_{2}^{+}+\mathrm{H}_{2} \mathrm{O}$ & $4.3 \times 10^{-10}$ & 51 \\
\hline 35 & $\mathrm{H}_{2} \mathrm{O}^{+}+\mathrm{H}_{2} \mathrm{O} \rightarrow \mathrm{H}_{3} \mathrm{O}^{+}+\mathrm{OH}$ & $1.7 \times 10^{-9}$ & 51 \\
\hline 36 & $\mathrm{H}_{3} \mathrm{O}^{+}+\mathrm{N}_{2} \mathrm{O}_{5} \rightarrow \mathrm{NO}_{2}^{+}+\mathrm{HNO}_{3}+\mathrm{H}_{2} \mathrm{O}$ & $5.5 \times 10^{-10}$ & 52 \\
\hline 37 & $\mathrm{O}^{-}+\mathrm{H}_{2} \mathrm{O} \rightarrow \mathrm{OH}^{-}+\mathrm{OH}$ & $1.4 \times 10^{-9}$ & 51 \\
\hline 38 & $O^{-}+O_{2}(a) \rightarrow O_{2}^{-}+O$ & $1 \times 10^{-10}$ & 51 \\
\hline 39 & $\mathrm{O}^{-}+\mathrm{O}_{3} \rightarrow \mathrm{O}_{3}^{-}+\mathrm{O}$ & $8 \times 10^{-10}$ & 51 \\
\hline 40 & $\mathrm{O}_{2}^{-}+\mathrm{O} \rightarrow \mathrm{O}^{-}+\mathrm{O}_{2}$ & $3.3 \times 10^{-10}$ & 51 \\
\hline 41 & $\mathrm{O}_{2}^{-}+\mathrm{O}_{3} \rightarrow \mathrm{O}_{3}^{-}+\mathrm{O}_{2}$ & $3.5 \times 10^{-10}$ & 51 \\
\hline 42 & $\mathrm{NO}^{-}+\mathrm{O}_{2} \rightarrow \mathrm{O}_{2}^{-}+\mathrm{NO}$ & $5 \times 10^{-10}$ & 51 \\
\hline 43 & $\mathrm{NO}_{2}^{-}+\mathrm{N}_{2} \mathrm{O}_{5} \rightarrow \mathrm{NO}_{3}^{-}+\mathrm{NO}_{3}+\mathrm{NO}$ & $\times 10^{-1}$ & 51 \\
\hline 44 & $\mathrm{NO}_{2}^{-}+\mathrm{NO} \rightarrow \mathrm{NO}^{-}+\mathrm{NO}_{2}$ & $2.75 \times 10^{-}$ & 99 \\
\hline 45 & $\mathrm{NO}_{2}^{-}+\mathrm{HNO}_{3} \rightarrow \mathrm{NO}_{3}^{-}+\mathrm{HNO}_{2}$ & & 27 \\
\hline 46 & $\mathrm{OH}^{-}+\mathrm{O}_{3} \rightarrow \mathrm{O}_{3}^{-}+\mathrm{OH}$ & $9 \times 10^{-10}$ & 100 \\
\hline 47 & $\mathrm{He}+\mathrm{O}^{-}+\mathrm{O}_{2} \rightarrow \mathrm{He}+\mathrm{O}_{3}^{-}$ & $1.1 \times 10^{-30} \times\left(T_{g} / 300\right)^{-1}$ & 101 \\
\hline 48 & $\mathrm{He}+\mathrm{O}^{+}+\mathrm{N}_{2}$ & $6 \times 10^{-29}\left(T_{g} / 300\right)^{-2}$ & 101 \\
\hline 49 & $\mathrm{He}+\mathrm{O}_{2}^{+}+\mathrm{O}_{2}$ & $3.9 \times 10^{-30}\left(T_{g} / 300\right)^{-3.2}$ & 101 \\
\hline 50 & $\mathrm{He}+\mathrm{N}_{2}^{+}$ & $5 \times 10^{-29}\left(T_{g} / 300\right)^{-1}$ & 101 \\
\hline 51 & $\mathrm{He}+\mathrm{N}^{+}$ & $4.6 \times 10^{-29}$ & 62 \\
\hline \multicolumn{4}{|c|}{ Collisional relaxation } \\
\hline 52 & $O\left({ }^{1} D\right)+N_{2}$ & $1.8 \times 10^{-11} \times \exp \left(107 / T_{g}\right)$ & 82 \\
\hline 53 & $N_{2}(B)+N_{2} \rightarrow N_{2}(A)+N_{2}$ & $5 \times 10^{-11}$ & 53 \\
\hline 54 & $H e+O\left({ }^{1} D\right.$ & $1.0 \times 10^{-13}$ & 45 \\
\hline \multicolumn{4}{|c|}{ Collisional detachment } \\
\hline 55 & $\mathrm{O}_{3}+e$ & $3 \times 10^{-10}$ & 51 \\
\hline 56 & $\mathrm{O}_{2}^{-}+\mathrm{O}_{3} \rightarrow \mathrm{O}_{3}+\mathrm{O}_{2}+e$ & $6 \times 10^{-10}$ & 102 \\
\hline 57 & $O \rightarrow O_{3}+e$ & $1.5 \times 10^{-10}$ & 51 \\
\hline 58 & $\mathrm{O}_{2}^{-}+\mathrm{O}_{2}(a) \rightarrow 2 \mathrm{O}_{2}+e$ & $2 \times 10^{-10}$ & 51 \\
\hline 59 & $\mathrm{OH}^{-}+\mathrm{O} \rightarrow \mathrm{HO}_{2}+e$ & $2 \times 10^{-10}$ & 100 \\
\hline 60 & $\mathrm{He}+\mathrm{O}_{3}^{-} \rightarrow \mathrm{He}+\mathrm{O}+\mathrm{O}_{2}+e$ & $3 \times 10^{-10}$ & 65 \\
\hline
\end{tabular}




\begin{tabular}{|c|c|c|c|}
\hline 61 & $\mathrm{He}+\mathrm{H}^{-} \rightarrow \mathrm{He}+\mathrm{H}+e$ & $8 \times 10^{-18}\left(T_{g} / 300\right)^{0.5}$ & \\
\hline 62 & $\mathrm{He}+\mathrm{NO}^{-} \rightarrow \mathrm{He}+\mathrm{NO}+e$ & $2.4 \times 10^{-13}$ & \\
\hline \multirow{2}{*}{\multicolumn{4}{|c|}{$\begin{array}{l}\text { Penning ionization } \\
63 \mathrm{He} e^{*}+\mathrm{O} \rightarrow \mathrm{O}^{+}+\mathrm{He}+e\end{array}$}} \\
\hline & & & \\
\hline 64 & $\mathrm{He}^{*}+\mathrm{O}_{2} \rightarrow \mathrm{O}_{2}^{+}+\mathrm{He}+e$ & $2.54 \times 10^{-10}\left(T_{g} / 300\right)^{0.5}$ & 45 \\
\hline 65 & $\mathrm{He}^{*}+\mathrm{H}_{2} \mathrm{O} \rightarrow \mathrm{He}+\mathrm{OH}^{+}+\mathrm{H}+e$ & $1.5 \times 10^{-10}$ & 74 \\
\hline 66 & $\mathrm{He}^{*}+\mathrm{H}_{2} \mathrm{O}_{2} \rightarrow \mathrm{He}+\mathrm{OH}^{+}+\mathrm{OH}+e$ & $7.8 \times 10^{-10}$ & 9 \\
\hline 67 & $\mathrm{He}^{*}+\mathrm{N}_{2} \rightarrow \mathrm{N}_{2}^{+}+\mathrm{He}+e$ & $5 \times 10^{-11}$ & 47 \\
\hline 68 & $\mathrm{He}^{*}+\mathrm{N}_{2} \rightarrow \mathrm{N}^{+}+\mathrm{N}+\mathrm{He}+e$ & $1 \times 10^{-10}$ & 65 \\
\hline 69 & $\mathrm{He}_{2}^{*}+\mathrm{O} \rightarrow 2 \mathrm{He}+\mathrm{O}^{+}+e$ & $3.6 \times 10^{-10}$ & 78 \\
\hline 70 & $\mathrm{He}_{2}^{*}+\mathrm{O}_{2} \rightarrow 2 \mathrm{He}+\mathrm{O}_{2}^{+}+e$ & $3.6 \times 10^{-10}$ & 78 \\
\hline 71 & $\mathrm{He}_{2}{ }^{*}+\mathrm{H}_{2} \mathrm{O}_{2} \rightarrow \mathrm{OH}^{+}+\mathrm{OH}+2 \mathrm{He}+e$ & $6 \times 10^{-10}$ & 9 \\
\hline 72 & $\mathrm{He}_{2}^{*}+\mathrm{N}_{2} \rightarrow 2 \mathrm{He}+\mathrm{N}_{2}^{+}+e$ & $3 \times 10^{-11}$ & 77 \\
\hline \multicolumn{4}{|c|}{ radiation } \\
\hline 73 & $N_{2}(B) \rightarrow N_{2}(A)$ & $.25 \times 10^{5}$ & 103 \\
\hline \multicolumn{4}{|c|}{ Neutral reactions } \\
\hline 74 & $N+N O \rightarrow N_{2}+O$ & $2.1 \times 10^{-11} \times \exp \left(100 / T_{g}\right)$ & 82 \\
\hline 75 & $\mathrm{~N}+\mathrm{NO}_{2} \rightarrow \mathrm{N}_{2} \mathrm{O}+\mathrm{O}$ & $5.8 \times 10^{-12} \times \exp \left(220 / T_{g}\right)$ & 82 \\
\hline 76 & $\mathrm{~N}+\mathrm{OH} \rightarrow \mathrm{H}+\mathrm{NO}$ & $7.5 \times 10^{-11}$ & 51 \\
\hline 77 & $\mathrm{~N}\left({ }^{2} \mathrm{D}\right)+\mathrm{NO} \rightarrow \mathrm{N}_{2} \mathrm{O}$ & $6 \times 10^{-11}$ & 53 \\
\hline 78 & $N\left({ }^{2} D\right)+\mathrm{O}_{2} \rightarrow \mathrm{NO}+\mathrm{O}$ & $1.5 \times 10^{-12} \times\left(T_{g} / 300\right)^{0.5}$ & 53 \\
\hline 79 & $N\left({ }^{2} D\right)+O_{2} \rightarrow N O+O\left({ }^{1} D\right)$ & $6 \times 10^{-12} \times\left(T_{g} / 300\right)^{0.5}$ & 53 \\
\hline 80 & $N_{2}(A)+N_{2}(A) \rightarrow N_{2}(I$ & $4 \times 10^{-10}$ & 82 \\
\hline 81 & $\mathrm{~N}_{2}(A)+\mathrm{N}_{2} \mathrm{O}$ & $8 \times 10^{-11}$ & 97 \\
\hline 82 & $\mathrm{~N}_{2}(A)+\mathrm{N}_{2} \mathrm{O} \rightarrow \mathrm{NO}+$ & $8 \times 10^{-11}$ & 97 \\
\hline 83 & $\mathrm{~N}_{2}(A)+\mathrm{O}_{2} \rightarrow \mathrm{N}_{2}+2 \mathrm{O}$ & $5 \times 10^{-12} \times \exp \left(-210 / T_{g}\right)$ & 82 \\
\hline 84 & $N_{2}(A)+O_{2} \rightarrow O_{2}(a)+N_{2}$ & $1 \times 10^{-12}$ & 97 \\
\hline 85 & $N_{2}(A)+O \rightarrow N O+N\left({ }^{2} D\right)$ & $7 \times 10^{-12}$ & 51 \\
\hline 86 & $N_{2}(A)+O \rightarrow O\left({ }^{1} D\right)+N_{2}$ & $2.3 \times 10^{-11}$ & 52 \\
\hline 87 & $\mathrm{~N}_{2}(B)+\mathrm{O}_{2} \rightarrow \mathrm{N}_{2}+2 \mathrm{O}$ & $3 \times 10^{-10}$ & 51 \\
\hline 88 & $\mathrm{O}+\mathrm{NO}_{2} \rightarrow \mathrm{NO}+\mathrm{O}_{2}$ & $6.5 \times 10^{-12} \times \exp \left(120 / T_{g}\right)$ & 82 \\
\hline 89 & $\mathrm{O}+\mathrm{NO}_{3} \rightarrow \mathrm{O}_{2}+\mathrm{NO}_{2}$ & $1.7 \times 10^{-11}$ & 82 \\
\hline 90 & $\mathrm{O}+\mathrm{OH} \rightarrow \mathrm{H}+\mathrm{O}_{2}$ & $2.2 \times 10^{-11} \times \exp \left(-350 / T_{g}\right)$ & 51 \\
\hline & $\mathrm{O}+\mathrm{HO}_{2} \rightarrow \mathrm{OH}+\mathrm{O}_{2}$ & $8.3 \times 10^{-11} \times \exp \left(-500 / T_{g}\right)$ & 51 \\
\hline
\end{tabular}




\begin{tabular}{|c|c|c|c|}
\hline 92 & $O\left({ }^{1} D\right)+H_{2} \rightarrow O H+H$ & $1.1 \times 10^{-10}$ & \\
\hline 93 & $\mathrm{O}\left({ }^{1} \mathrm{D}\right)+\mathrm{H}_{2} \mathrm{O} \rightarrow \mathrm{OH}+\mathrm{OH}$ & $2.2 \times 10^{-10}$ & \\
\hline 94 & $\mathrm{O}_{2}(a)+\mathrm{O}_{3} \rightarrow O+2 \mathrm{O}_{2}$ & $5.2 \times 10^{-11} \times \exp \left(-2840 / T_{g}\right)$ & \\
\hline 95 & $\mathrm{O}_{3}+\mathrm{H} \rightarrow \mathrm{OH}+\mathrm{O}_{2}$ & $2.8 \times 10^{-11} \times\left(T_{g} / 300\right)^{0.75}$ & \\
\hline 96 & $\mathrm{NO}+\mathrm{NO}_{3} \rightarrow 2 \mathrm{NO}_{2}$ & $1.8 \times 10^{-11} \times \exp \left(110 / T_{g}\right)$ & 82 \\
\hline 97 & $\mathrm{NO}_{2}+\mathrm{H} \rightarrow \mathrm{OH}+\mathrm{NO}$ & $1.47 \times 10^{-10}$ & 51 \\
\hline 98 & $\mathrm{OH}+\mathrm{H}_{2} \mathrm{O}_{2} \rightarrow \mathrm{HO}_{2}+\mathrm{H}_{2} \mathrm{O}$ & $2.9 \times 10^{-12} \times \exp \left(-160 / T_{g}\right)$ & 83 \\
\hline 99 & $\mathrm{OH}+\mathrm{HNO}_{2} \rightarrow \mathrm{NO}_{2}+\mathrm{H}_{2} \mathrm{O}$ & $1.8 \times 10^{-11} \times \mathrm{e}$ & 27 \\
\hline 100 & $\mathrm{He}+2 \mathrm{O} \rightarrow \mathrm{He}+\mathrm{O}_{2}$ & $1.3 \times 10^{-32}\left(T_{g} / 300\right)^{-1} \exp \left(-170 / T_{g}\right)$ & 45 \\
\hline 101 & $\mathrm{He}+\mathrm{O}_{2}+\mathrm{O} \rightarrow \mathrm{He}+\mathrm{O}_{3}$ & $3.4 \times 10^{-34}\left(T_{g} / 300\right)^{-}$ & 45 \\
\hline 102 & $\mathrm{He}+\mathrm{NO}+\mathrm{O} \rightarrow \mathrm{He}+\mathrm{NO}_{2}$ & $1 \times 10^{-31}$ & 79 \\
\hline 103 & $\mathrm{He}+\mathrm{H}+\mathrm{O}_{2} \rightarrow \mathrm{He}+\mathrm{HO}_{2}$ & $2 \times 10^{-32}\left(T_{g} / 300\right)^{-}$ & 81 \\
\hline 104 & $\mathrm{He}+2 \mathrm{OH} \rightarrow \mathrm{He}+\mathrm{H}_{2} \mathrm{O}_{2}$ & $3.96 \times 10^{-31}\left(T_{g} / 300\right)^{-3.2}$ & 81 \\
\hline 105 & $\mathrm{He}+\mathrm{O}+\mathrm{NO}_{2} \rightarrow \mathrm{He}+\mathrm{NO}_{3}$ & $9 \times 10^{-32}\left(300 / T_{g}\right)^{2}$ & 82 \\
\hline 106 & $\mathrm{He}+\mathrm{NO}+\mathrm{OH} \rightarrow \mathrm{He}+\mathrm{HNO}_{2}$ & $7.4 \times 10^{-31}\left(300 / T_{g}\right)^{2.4}$ & 82 \\
\hline 107 & $\mathrm{He}+\mathrm{NO}_{2}+\mathrm{NO}_{3} \rightarrow \mathrm{He}+\mathrm{N}_{2} \mathrm{O}_{5}$ & $2.8 \times 10^{-30}\left(300 / T_{g}\right)^{3.5}$ & 83 \\
\hline 108 & $\mathrm{He}+\mathrm{NO}_{2}+\mathrm{OH} \rightarrow \mathrm{He}+\mathrm{HNO}_{3}$ & $2.2 \times 10^{-30}\left(300 / T_{g}\right)^{2.9}$ & 82 \\
\hline 109 & $\mathrm{He}^{*}+2 \mathrm{He} \rightarrow \mathrm{He}_{2}^{*}+\mathrm{He}$ & $1,5 \times 10^{-34}$ & 78 \\
\hline
\end{tabular}

$\mathrm{T}_{\mathrm{e}}$ in $\mathrm{eV}, \mathrm{T}_{\mathrm{g}}$ in Kelvin

${ }^{a}$ The rate coefficient is obtained from EEDF using cross sections from indicated reference.

${ }^{\mathrm{b}}$ Rate coefficient is in $\mathrm{cm}^{3} / \mathrm{s}$ for two-body reactions and $\mathrm{cm}^{6} / \mathrm{s}$ for three-body reactions 


\section{Reference}

[1] Tian L, Nie H, Chatterton N P, Branford-White C J, Qiu Y and Zhu L 2011 Appl. Surf. Sci. 257 7113-8

[2] Gonzalez II E, Barankin M D, Guschl P C and Hicks R F 2010 Plasma Process. Polym. 7 482-93

[3] Furusho H, Kitano K, Hamaguchi S and Nagasaki Y 2009 Chem. Mater. $213526-35$

[4] Ikawa S, Kitano K and Hamaguchi S 2010 Plasma Process. Polym. 7 $33-42$

[5] O'connell D, Cox L J, Hyland W B, Mcmahon S J, Reuter S, Graham W G, Gans T and Currell F J 2011 Appl. Phys. Lett. 98043701

[6] Zhu W C, Li Q, Zhu X M and Pu Y K 2009 J. Phys. D: Appl. Phys. 42 202002

[7] Yonemori S, Nakagawa Y, Ono R and Oda T 2012 J. Phys. D: Appl. Phys. 45225202

[8] Yuan X, Raja L L. 2002 Appl. Phys. Lett. 81 814-16

[9] Liu D X, Bruggeman P, Iza F, Rong M Z and Kong M G 2010 Plasma Sources Sci. Technol. 19025018

[10] Liu D X, Rong M Z, Wang X H, Iza F, Kong M G and Bruggeman P 2010 Plasma Process. Polym. 7 846-65

[11] Bourdon A, Darny T, Pechereau F, Pouvesle J-M, Viegas P, Iséni S and Robert E 2016 Plasma Sources Sci. Technol. 25035002

[12] Tschiersch R, Bogaczyk M and Wagner H E 2014 J. Phys. D: Appl. Phys. 47365204

[13] Ellerweg D, Benedikt J, von Keudell A, Knake N and Schulz-von der Gathen V 2010 New J. phys. 12013021

[14] Wang S, Chen Z Y, Wang X H, Li D, Yang A J, Liu D X, Rong M Z, Chen H L and Kong M G 2015 J. Appl. Phys. 118203301

[15] Massines F, Rabehi A, Decomps P, Gadri R B, Segur P and Mayoux C 1998 J. Appl. Phys. 83 2950-7

[16] Samukawa S et al 2012 J. Phys. D: Appl. Phys.45 253001

[17]Breden D, Miki K and Raja L L 2012 Plasma Sources Sci. Technol. 21 034011

[18] Naidis G V. 2011 J. Phys. D: Appl. Phys. 44215203.

[19] van Gaens W and Bogaerts A 2013 J. Phys. D: Appl. Phys. 46275201 [20] Murakami T, Niemi K and Gans T 2013 Plasma Sources Sci. Technol.22 015003

[21] Tavant A and Lieberman M A 2016 J. Phys. D: Appl. Phys. 49 465201

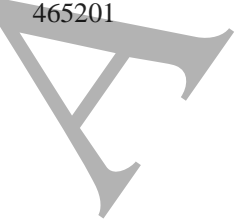

[22] Liu D X, Iza F, Wang X H, Kong M G and Rong M Z 2011 Appl. Phys. Lett.98 221501

[23] Vasko C A, Liu D X, Van Veldhuizen E M, Iza F and Bruggeman P J 2014 Plasma Chem. Plasma Process. 34 1081-99

[24] Yang A J, Wang X H, Rong M Z, Liu D X, Iza F and Kong M G 2011 Phys. Plasmas 18113503

[25] Liu D, Sun B, Iza F, Xu D H, Wang X H, Rong M Z and Kong M G 2017 Plasma Sources Sci. Technol. 26045009

[26] Sakiyama Y, Graves D B, Chang H W, Shimizu T and Morfill G E 2012 J. Phys. D: Appl. Phys. 45425201

[27] Dorai R and Kushner M J 2003 J. Phys. D: Appl. Phys. 36666

[28] Hagelaar G J M and Pitchford L C 2005 Plasma Sources Sci. Technol. 14722

[29] Kushner M J 1999 Bull. Am. Phys. Soc.44 63 [30] Perin J, Leroy O and Bordage M C 1996 Contrib. Plasma Phys. 363 [31] Ding K, Lieberman M A and Lichtenberg A J 2014 J. Phys. D: Appl. Phys. 47305203

[32] Yang A J, Wang X H, Rong M Z, Liu D X, Iza F and Kong M G 2011 Phys. Plasmas 18113503

[33] Liu D X, Iza F, Wang X H, Ma Z Z, Rong M Z and Kong M G 2013 Plasma Sources Sci. Technol. 22055016

[34] Murakami T, Niemi K, Gans T, O’Connell D and Graham W G 2012 Plasma Sources Sci. Technol. 22015003

[35] Itikawa Y, Ichimura A, Onda K, Sakimoto K, Takayanagi K, Hatano Y, Hayashi M, Nishimura H and TsurubuchiS 1989 J. Phys. Chem. Ref. Data 1823

[36] Lieberman M A 2015 Plasma Sources Sci. Technol. 24025009.

[37] Van Gaens W and Bogaerts A 2013 J. Phys. D: Appl. Phys. 46275201 [38] Malik M A, Ghaffar A and Malik S A 2001 Plasma Sources Sci. Technol. 1082

[39] Ding K and Lieberman M A 2015 J. Phys. D: Appl. Phys.48 035401 [40] Yang A, Liu D, Rong M, Wang X H and Kong M G 2014 Phys. Plasmas 21083501

[41] Rauf S and Kushner M J 1999 J. App. Phys. 853460

[42] Stalder K R, Vidmar R J, Nersisyan G and Graham W G 2006 J. Appl. Phys. 99093301

[43] Emmert F, Angermann H H, Dux R and Langhoff H 1988 J. Phys. D: Appl. Phys. 21667

[44] Quinteros T, Gao H, DeWitt D R, Schuch R, Pajek, M, Asp S and Belki'c D̃z 1995 Phys. Rev. A 511340 
[45] Stafford D S and Kushner M J 2004 J. Appl. Phys. 962451

[46] Kong M G and Deng X T 2003 IEEE Trans. Plasma Sci. 317

[47] Golubovskii Yu B, Maiorov V A, Behnke J and Behnke J F 2003 J. Phys. D: Appl. Phys. 3639

[48] Miller T J, Farquhar P R and Willacy K 1997 Astrom. Astrophys. Suppl. Ser. 121139

[49] Bortner M H and Baurer T 1972 Defense Nuclear Agency reaction rate handbook, Final report (No. AD--763699; DNA--1948-H). General Electric Co., Philadelphia, Pa.(USA).

[50] Deloche R, Monchicourt P, Cheret M, and Lambert F 1976 Phys. Rev. A 13 1140-76

[51] Capitelli M, Ferreira C M, Gordiets B F and Osipov A I 2000 Plasma Kinetics in Atmospheric Gases (Berlin: Splinger)

[52] Matzing H 2007 Adv. Chem. Phys. 80 315-402

[53] Kossyi I A, Kostinsky A Yu, Matveyen A A and Silakov V P 1992 Plasma Sources Sci. Technol. 1207

[54] Kraemer W P, Spirko V and Jurek M 1995 Chem. Phys. Lett. 236 $177-83$

[55] Ikezoe Y, Matsuoka S, Takebe M and Viggiano A 1987 Gas Phase Ion-Molecule Reaction Rate Constants Through 1986 (Tokyo: Maruzen)

[56] Albritton D L 1978 At. Data Nucl. Data Tables 221

[57] Sakiyama Y and Graves D B 2009 Plasma Sources Sci. Technol. 18 025022

[58] Binns W R and Ahl J L 1978 J. Chem. Phys. 68 538-46

[59] Sanders R A and Muschlitz E E 1977 Int. J. Mass Sepctro. Ion Phys. 23 99-108

[60] Jurek M, Spirko V and Kraemer W P 1995 Chem. Phys. 193 287-96

[61] Eichwald O, Yousfi M, Hennad A and Benabdessadok M D $1997 \mathrm{~J}$. Appl. Phys. 824781

[62] Mark T D and Oskam H J 1971 Phys. Rev. A 41445

[63] Sommerer T J and Kushner M J 1992 J. Appl. Phys. 71 1654-73

[64] Wynn M J and Martin J D 1970 J. Chem. Phys. 52 191-7

[65] Vidmar R J and Stalder K R 2004 AFOSR Final Performance Report. (Computations of the power to sustain plasma in air with relevance to aerospace technology. Final report prepared for Air Force Office of Scientific Research. Report No: AFRISRARRE040123. Contact No. F49620-01-0414. 20 Febraury 2004)

[66] Champion R L, Doverspike L D and Lam S K 1976 Phys. Rev. A 13 $617-21$

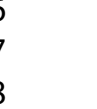

[67] Axford S D T and Hayhurst A N 1996 Proc. Math. Phys. Eng. Sci. 452 1007-33

[68] McDaniel E W, Flannery M R, Thomas E W, Ellis H W, McCann K J, Manson S T, Gallagher J W, Rumble J R, Beaty E C and Roberts T G 1978 US Army Missile Research and Development Command Technical Report No H-78-1

[69] Wang Q, Economou D J and Donnelly V M 2006 J. Appl. Phys. 100 023301

[70] Cardoso R P, Belmonte T, Henrion G and Sadeghi N 2006 J. Phys. D: Appl. Phys. 39 4178-85

[71] Hagelaar G J M and Kroesen GM W 2000 J. Appl. Phys. 885

[72] Adams N G, Bohme D K and Ferguson E E 1970 J. Chem. Phys. 52 $5101-5$

[73] Ivanov V A and Skoblo Yu E 2005 Opt. Spectrosc. 98 811-818

[74] Shibata T, Fu8kuyama T and Kuchitsu K 1973 J. Mass Spectrom. Soc. Jpn. 21 217-21

[75] Takao S, Kogoma M, Oka T, Imamura M and Arai S 1980 J. Chem. Phys. 73 148-55

[76] Ricard A, Decomps Ph and Massines F 1999 Surf. Coat. Technol. 112 $1-4)$

[77] Martens T, Bogaerts A, Brok W J M and Dijk J V 2008 Appl. Phys. Lett. 92041504

[78] Niemi K, Waskoenig J, Sadeghi N, Gans T and O’Connell D 2011 Plasma Sources Sci. Technol. 20055005

[79] Castillo M, M'endez I, Islyaikin A M, Herrero V J and Tanarro I 2005 J. Phys. Chem. A 1096255

[80] Tsang W and Hampson R F 1986 J. Phys. Chem. Ref. Data 15 $1087-222$

[81] GRI-MECH 3 Reaction Rate Database.

http://www.me.berkeley.edu/gri-mech/

[82] Herron J T and Green D S 2001 Plasma Chem. Plasma Process. 21 459

[83] Atkinson R, Baulch D L, Cox R A, Hampson R F, Kerr J A, Rossi M J and Troe J 1997 J. Phys. Chem. Ref. Data 261329

[84] National Institute of Standards and Technology, cited 2011: NIST Chemical Kinetics Database (Available online at http://kinetics.nist.gov/) [85] Person J C and Ham D O 1988 Int. J. Radiat. Appl. Instrum. Part C 31

[86] Henry R, Burke P and Sinfailam A L 1969 Phys. Rev. 178 218-25 
[87] Malone C P, Johnson P V, Liu X, Ajdari B, Kanik I and Khakoo M A 2012 Phys. Rev. A 85062704

[88] Laher R R and Gilmore F R 1990 J. Phys. Chem. Ref. Data 19 277-305

[89] Eliasson B and Kogelschatz U 1986 Basic data for modelling of electrical discharges in gases: oxygen(ABB Asea Brown Boveri).

[90] Yousfi M and Benabdessadok M D 1996 J. Appl. Phys. 806619

[91] Itikawa Y and Mason N 2005 J. Phys. Chem. Ref. Data 34 1-22

[92] Samiolovich V G, Popovich M P, Emelyanov Yu M and Filippov Yu V 1966 J. Phys. Chem.40 287

[93] Rapp D and Briglia D D 1965 J. Chem. Phys. 43 1480-9

[94] McConkey J W, Malone C P, Johnson P V, Winstead C, Mckoy V and Kanik 2008 Phys. Rep. 466 1-103

[95] McConkey J W, Malone C P, Johnson P V, Winstead C, McKoy V and Kanik I 2008 Phys. Rep.466 1

[96] Itikawa Y and Mason N 2005 J. Phys. Chem. Ref. Data34 1-22

[97] Matzing H 2007 Adv. Chem. Phys. 80 315-402

[98] Sieck L W, Herron J T and Green D S 2000 Plasma Chem. Plasma Process. 20235

[99] Anicich V G 1993 J. Phys. Chem. Ref. Data 221469

[100] Olson R E, Peterson J R and Moseley J T 1970 J. Chem. Phys. 53 3391

[101] Bortner M H and Baurer T 1979 Defense Nuclear Agency Reaction

Rate Handbook Second Edition, Section 24 Revision No 7, NTIS AD-763699

[102] Cenian A, Chernukho A and Borodin V 1995 Contrib. Plasma Phys. 35273

[103] Tochikubo F and Arai H 2002 Japan. J. Appl. Phys. 41844

[104] Kushner M J 1993 J. Appl. Phys. 746538

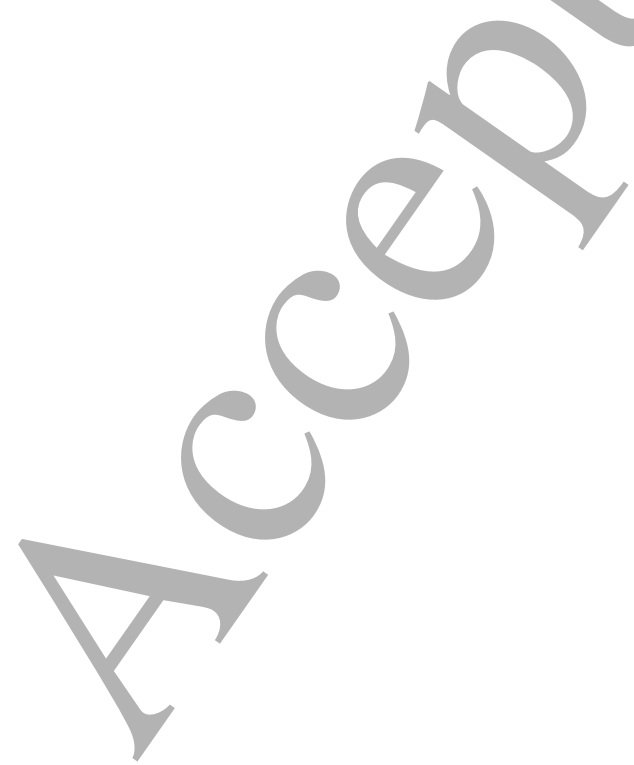

